NBER WORKING PAPER SERIES

\title{
DOES FOOD AID HARM THE POOR? HOUSEHOLD EVIDENCE FROM ETHIOPIA
}

\author{
James Levinsohn \\ Margaret McMillan \\ Working Paper 11048 \\ http://www.nber.org/papers/w11048
}

\author{
NATIONAL BUREAU OF ECONOMIC RESEARCH \\ 1050 Massachusetts Avenue \\ Cambridge, MA 02138 \\ January 2005
}

The views expressed herein are those of the author(s) and do not necessarily reflect the views of the National Bureau of Economic Research.

(C) 2005 by James Levinsohn and Margaret McMillan. All rights reserved. Short sections of text, not to exceed two paragraphs, may be quoted without explicit permission provided that full credit, including () notice, is given to the source. 
Does Food Aid Harm the Poor? Household Evidence from Ethiopia

James Levinsohn and Margaret McMillan

NBER Working Paper No. 11048

January 2005

JEL No. F1, O1

\section{ABSTRACT}

This paper uses household-level data from Ethiopia to investigate the impact of food aid on the poor.

We find that food aid in Ethiopia is "pro-poor." Our results indicate that (i) net buyers of wheat are poorer than net sellers of wheat, (ii) there are more buyers of wheat than sellers of wheat at all levels of income, (iii) the proportion of net sellers is increasing in living standards and (iv) net benefit ratios are higher for poorer households indicating that poorer households benefit proportionately more from a drop in the price of wheat. In light of this evidence, it appears that households at all levels of income benefit from food aid and that - somewhat surprisingly - the benefits go disproportionately to the poorest households.

James Levinsohn Department of Economics University of Michigan Ann Arbor, MI 48109-1220

and NBER

james1@umich.edu

Margaret McMillan

Tufts University

mmcmilla@tufts.edu 
Does Food Aid Harm the Poor?

Household Evidence from Ethiopia ${ }^{1}$

\author{
by \\ James Levinsohn \\ University of Michigan \\ National Bureau of Economic Research \\ Margaret McMillan \\ Tufts University
}

In developing countries, food aid undermines local agriculture and creates dependence on imports. Many of the US's biggest markets - from Egypt to Colombia and Nigeriaonce received large amounts of food aid. The arrival of US surpluses effectively drove down local prices, undermined investment in farming and created this dependence on imports."

Kevin Watkins, Head of Research, Oxfam (The Independent, October, 18, 2003)

"Food aid is a unique resource for addressing hunger and nutrition problems, addressing emergency food needs, supporting development programs, and directly feeding vulnerable groups. The United States is continuing its efforts to better target and increase the effectiveness of its food aid programs, while continuing their fundamental humanitarian nature."

Ann M. Veneman, U.S. Secretary of Agriculture, (Economic Perspectives, March, 2002)

Food aid is supposed to provide relief for the poor. Yet, by increasing the supply of food, food aid may actually reduce prices and farmers' incomes and ultimately discourage domestic production ${ }^{2,3}$. In developing countries, since the poor tend to be

\footnotetext{
${ }^{1}$ We thank Nzinga Broussard for excellent research assistance, participants in the NBER conference on Globalization and Poverty and especially Rohini Pande for helpful comments.

2 Though food aid can take several different forms, some part of all types of food aid (including emergency relief) is sold on local markets and therefore either competes against domestic production or reduces the demand for commercial imports (Abbott et al, 2003).
} 
farmers and concentrated in rural areas, most people assume that the negative impact of food aid will be felt disproportionately by the poor. However, most food aid is a byproduct of policies designed to aid farmers in rich countries, by disposing of surplus agricultural commodities. Thus, far from being created to help the poor, these policies are actually part of the overall agricultural policies of the rich countries. Such policies have been severely criticized during the most recent round of WTO negotiations, and many researchers claim that food aid policies are responsible for keeping the poor, poor.

However, as Panagariya notes (Arvind Panagariya, 2002), the claim that these interventions in agriculture in the OECD countries are hurting poor countries is not grounded in facts. Forty-eight of the world's sixty-three poorest countries were actually net food importers during the period 1995-97 (Valdes and McCalla, 1999), thus, the removal of wealthy countries' subsidies on food products would lead to welfare losses for most of the world's poorest countries. This still leaves unanswered the question of what happens to the poorest members of the poor countries. Within any country, households that are net buyers of cereals would be hurt by a price increase, while households that are net sellers of cereals would see their welfare increase with cereals prices. Thus, the effect of a change in price on the poor depends on whether poor households are net buyers or net sellers of cereals. Therefore, one way to study the impact of these policies on the poor is to use the household as the unit of analysis.

Broadly speaking, the existing research on food aid can be divided into two areas - research on the disincentive effects of food aid and research on the efficacy with which food aid has been targeted. The work on the disincentive effects of food aid typically uses aggregate data to estimate country-level supply and demand equations. These estimates are then used to derive multipliers for determining the cumulative impact of food aid on

\footnotetext{
${ }^{3}$ The idea that food aid could harm the poor was raised as a theoretical possibility by Nobel laureate Theodore Schultz (Schultz, 1960). In the United States, the potential disincentive effects of food aid were officially recognized by the Bellmon Amendment to Public Law $480^{3}$ which sets out the following criteria for approving a food aid program: "1. The distribution of commodities in the recipient country will not result in a substantial disincentive or interference with domestic production or marketing in that country; and 2. Adequate storage facilities are available in the recipient country at the time of exportation of the commodity to prevent the spoilage or waste of the commodity." (Amendment to Section 401 (b) of United States Public Law 480, 1977)
} 
domestic production and trade via the impact of food aid on the domestic price (see for example Bezuneh et al, 2003) ${ }^{4}$. Less work has been done on the issue of targeting, at least in part because household data on the receipt of food transfers is usually unavailable (Jayne et al, 2002). The work that has been done typically uses household data and asks who is getting food aid and why. Our work is most closely related to recent work by Jayne et al (2002) who study the targeting of food aid in rural Ethiopia. These authors use nationally representative rural household data from Ethiopia collected in 1996 to study the extent to which food aid is targeted to poor households and communities. They find that food aid does not tend to go to the poorest households and that there tends to be inertia in the distribution of food aid.

We ask a slightly different question - does food aid have the potential to help the poor in Ethiopia? In other words, who are the poor and are they selling the items distributed by food aid programs. In theory, food aid could still hurt the poor if it lowered prices for poor net sellers of food and markets were sufficiently segmented that it didn't lower prices for poor net buyers of food. This theoretical possibility seems practically implausible for at least two reasons. First, according to Harrison (2002), there is a high degree of serial and spatial correlation between producer and consumer prices of grain ${ }^{5}$. And second, though Jayne et al (2002) and Dercon et al (2003) find evidence of imperfect targeting, they do find that poorer households are significantly more likely to receive food aid. They also find that women, children and the elderly are more likely to receive food aid.

In addition, we use more recent data (1999/2000) and a sample that includes not just rural households, but also urban households. Including urban households is particularly important for our study because one of the criticisms of food aid is that it is used to feed the relatively better off urban residents at the expense of poor rural farmers.

\footnotetext{
${ }^{4}$ A body of work similar to this although using less sophisticated econometric techniques is reviewed by Maxwell and Singer (1970) who conclude that price disincentives can be avoided by an appropriate mix of policy.

${ }^{5}$ One drawback of the analysis by Harrison (2002) and others is that they are based on prices between major wholesale centers. According to Gabre-Madhin, there is some evidence that markets in remote areas
} 
Finally, we obtain empirical estimates of the likely impact of food aid on cereals prices using a standard supply and demand framework.

We choose to focus on Ethiopia for several reasons. Ethiopia receives more food aid than almost any other country in the world. Food aid reached 15\% of annual cereal production in 2003 and typically represents between 5 to 15 percent of total annual cereal production (Jayne et al., 2002, WFP, 2004). At the same time, it is widely recognized that raising the productivity and profitability of smallholder agriculture is essential for poverty reduction in Ethiopia. In 1992, the Ethiopian government launched its' poverty reduction strategy of Agricultural Development Lead Industrialization (ADLI). The centerpiece of this strategy has been a massive extension program aimed at diffusing agricultural technology dubbed PADETES for Participatory Demonstration and Training Extension System. Recent work by the Ethiopian Economic Association (EEA) ${ }^{6}$ suggests that the results of ADLI have been somewhat disappointing. For most crops, average yields have remained stagnant, in spite of increased imports of agricultural inputs. Average farm size has declined and prices have fallen, leaving many farmers worse off than they were when ADLI began (Hamory and McMillan, 2002). While it is unlikely that food aid alone is responsible for the failure of PADETES, it is conceivable that food aid has contributed to the decline in prices.

Interestingly, at the most recent meetings of the Ethiopian Economics Association (June, 2004), in a presentation titled "Globalization, Its' Promises and Perils to the Ethiopian Economy," author, Amdetsion GebreMichael claimed that:

"One major problem facing farmers has been the absence of appropriate policy instruments to stabilize farm gate price and to safeguard the income of small farmers. In the case of cereal prices, the absence of such a policy combined with uncoordinated food aid flows, has led to depressed cereal farm gate prices - often to levels below costs of production."

are not as well integrated. In future work, we plan to test this hypothesis using HICE data on unit values appropriately adjusted for quality.

${ }^{6}$ Annual Report on the Ethiopian Economy, Vols. I and II. 
GebreMichael goes on to argue that the downward pressure on cereals prices owing in part to the uncoordinated delivery of food aid has undoubtedly reduced farmers' incentives to enhance productivity and increase output. The author provides no evidence for this statement, but does cite a report by a consultant to the World Bank that makes the same claim (Harrison, 2002).

We take the household as our basic unit of analysis and we ask whether households are net buyers or sellers of the basic foodstuffs typically distributed in the form of food aid. The first order approximation of the welfare effect of food aid is net production of the commodity multiplied by the change in the price of the commodity caused by food aid (see Deaton $(1989,1997)$ for a more detailed discussion). Thus, if a household buys more wheat than it sells, we call that household a net buyer of wheat. Since food aid is expected to depress food prices, food aid will benefit net food buyers and harm net food sellers. To determine the poverty impact of food aid, we then classify households according to expenditure per capita on an adult equivalency basis and ask whether the households classified as poor are net buyers or net sellers of food.

Finally, we obtain some rough estimates of the magnitude of the price change caused by food aid and hence the magnitude of the first order welfare effects of an increase in the price of food. To do this, we use supply and demand elasticities for cereals, combined with information on total cereals production and cereals food aid to identify the equilibrium price and quantity of cereals in the absence of food aid. Using the equilibrium price and quantity in the absence of food aid and the observed prices and quantities, we obtain an estimate of the aggregate welfare effects of the price change associated with eliminating food aid ${ }^{7}$. In future work we hope to refine this analysis by using the household data to compute regional elasticity estimates and by using regional data on food aid and food production to compute welfare effects by region.

\footnotetext{
${ }^{7}$ The Ethiopian government has no official restrictions on commercial imports of wheat or other grains. However, Ethiopia imports virtually no grains on a commercial basis. In 1999, commercial imports of wheat amounted to only six percent of all wheat imports - these were imported by four large food processing companies based in Addis Ababa. Ethiopia does not import wheat or any other grain on a commercial basis because transport costs are prohibitive. Thus, "dumping" of food aid will depress market prices. This hypothesis has been tested and confirmed in a recent review of grain marketing in Ethiopia (Harrison (2002)).
} 
Our household data come from two surveys conducted by the Central Statistical Authority (CSA) of the Government of Ethiopia. The Household Consumption and Expenditure Survey $1999 / 2000$ is a nationally representative survey that covers 17,332 households. The Welfare Monitoring Survey is also nationally representative and covers 25,917 households. Our food aid data comes from Ethiopia's Disaster Prevention and Preparedness Committee and the World Food Programme. Our data on national cereals production comes from the CSA.

Our results indicate that (i) net buyers of wheat are poorer than net sellers of wheat, (ii) there are more buyers of wheat than sellers of wheat at all levels of income, (iii) the proportion of net sellers is increasing in living standards and (iv) net benefit ratios are higher for poorer households indicating that poorer households benefit proportionately more from a drop in the price of wheat. In light of this evidence, it appears that households at all levels of income benefit from food aid and that - somewhat surprisingly - the benefits go disproportionately to the poorest households. Several caveats must be kept in mind. First, even the non-parametric regressions are averages by income category and so could mask underlying trends. The extent to which these averages reflect the true effects of price changes on poverty depend on whether these averages truly represent the typical household, or whether there is a significant amount of variation among poor households even at the poorest income levels. Second, it is important to note that we do not attempt to quantify the possible dynamic effect of higher food prices. It is possible that higher food prices, by increasing the incentives to invest in agriculture, could eventually lead to lower food prices.

In interpreting our results, it is also important to note that we are considering only the effects of food aid that is imported into the country and not food aid that is purchased from local farmers and redistributed. An increasing amount of food aid is purchased locally. However, the most donors do not purchase any food aid locally but rather purchase the food from their own farmers for distribution in Ethiopia. It may be that local 
purchase is a preferable alternative for Ethiopians, however, at least so far, it has not been deemed a politically feasible option for the majority of the donating countries.

Recently, the United States has been heavily criticized for refusing to purchase food aid locally. However, it is important to note that this appears to be a widespread sentiment not reserved for the United States. For example, in 1999, 663 thousand metric tonnes of wheat food aid were imported into Ethiopia while only 30 thousand metric tonnes of wheat food aid were purchased locally. Of the 663 thousand M/T that were imported, only $21 \%$ came directly from the United States $-31 \%$ came from the World Food Programme, and 32\% from the European Community. In 2000, the numbers look similar $-1,074$ thousand M/T of wheat food aid were imported and only 59 thousand $\mathrm{M} / \mathrm{T}$ were purchased locally ${ }^{8}$.

The remainder of the paper is organized as follows: Section 2 describes our methodology. Section 3 describes our data and presents descriptive statistics. Section 4 presents our results. Section 5 considers the impact of food aid on cereals prices and Section 6 synthesizes our conclusions.

\section{Methodology}

The approach we use follows Deaton (1989) and considers the impact of changes in cereals prices on the distribution of income. In general, households that are net sellers of cereals will gain from higher prices while net buyers will lose. Changes in these prices will affect the distribution of real income between urban and rural areas as well as the distribution within sectors depending on the relationship between living standards and the net consumption and production of cereals.

Many rural households are both producers and consumers of these products and the empirical strategy takes this into account. Following Deaton (1989) we model the effects of price changes using an indirect utility function in which the household's utility is

\footnotetext{
${ }^{8}$ See Table 3 for details and sources.
} 
written as a function of its income and prices. (Note that we ignore savings.) These effects can be summarized in the following way:

$$
\frac{\partial W}{\partial \ln p_{\text {cereal }}}=\sum_{h} \theta_{h}\left(x_{h}, z_{h}\right) p_{h, \text { cereal }}\left(y_{h, \text { cereal }}-c_{h, \text { cereal }}\right) / x_{h}
$$

where, $\mathrm{W}$ is the social welfare function, theta captures the social marginal utility of money, $\mathrm{h}$ is household, $\mathrm{x}$ is the household's total consumption, $\mathrm{z}$ are household characteristics, $\mathrm{y}$ is household production of the food crop and $\mathrm{c}$ is household consumption of the food crop. The general approach is to calculate net benefit ratios for each household and to examine the distribution of these ratios in relation to living standards and region ${ }^{9}$. As noted by Deaton, higher food prices are likely to redistribute real income from the urban to rural sectors. What is less obvious is how price changes redistribute real income between the rich and poor within the rural sector.

Note that these are only the first order effects of price changes that ignore both the partial equilibrium effects of food price changes on quantities demanded and supplied as well as the general equilibrium effects on employment patterns, wages, the price of other factors and technological innovation. Accounting for these effects would require a general equilibrium model similar to that employed by Porto (2003).

Our approach is best thought of as a good approximation to what would happen in the short run (see Panagariya 2000, Barett 1996). We focus on these short run changes for several reasons. First and most importantly, using short run changes seems to be most appropriate for studying the impact of price changes on the poor, who as Barrett and Dorosh (August 1996) say are "likely to be teetering on the brink of survival" and less able to take advantage of supply side effects of price changes. We are also limited by our data. To the extent that food aid drives prices down, food aid may act as a disincentive to food production over the long run. We do not have time series data and so are unable to

\footnotetext{
${ }^{9}$ For a complete discussion of this type of analysis and its limitations see The Analysis of Household Surveys: A Microeconometric Approach to Development Policy, World Bank 1997.
} 
directly test this hypothesis. However, for all five cereals produced in Ethiopia, there is an upward trend in production over the period 1980-2000 (Hamory and McMillan, 2001).

As we mentioned earlier, it is important to disaggregate the analysis. Though the agricultural sector might benefit as a whole from higher food prices, aggregation could disguise a highly concentrated intrasectoral distribution of the benefits and costs of food price changes. Following standard procedure, we use per capita consumption as a conditioning variable. In future work, we intend to condition on land holdings and per capita income.

Our approach is to study the way in which the net benefit ratio varies according to living standards. The ratio is unitless and measures the elasticity of real income with respect to a price change. The manner in which the net benefit ratio varies across the income distribution tells us something about how the price change affects households across the distribution of income. For this reason, we estimate the net benefit ratio relative to measures of per capita expenditure or the conditional expectation of the net benefit ratio given a household's expenditure.

Note, that we could simply run a linear regression with the net benefit ratio as the dependent variable and per capita expenditure as the explanatory variable. However, to avoid the problems associated with specifying a functional form, we choose instead to analyze the net benefit ratios using the nonparametric techniques introduced by Angus Deaton (1989). The advantage of using nonparametric techniques is that it "lets the data do the talking." Readers are directed elsewhere for a comprehensive treatment of the nonparametric techniques employed here.

We also estimate density functions of the per capita expenditure (adult equivalent) according to whether individuals are net buyers or sellers of cereals. In the univariate case, the best way to conceptualize what we are doing is to imagine first creating a histogram where the heights of the bars represent the proportion of the population falling within a given band. The problem with the histogram is the arbitrariness of the choice of 
the number of bands and their width. Kernel estimates of the density function allow us to "smooth" the histogram and place confidence intervals around the distribution. In the univariate case, the kernel estimate of the density function of per capita expenditure, $\mathrm{x}$, is given by:

$$
\hat{f}(x)=\frac{1}{n h} \sum_{i=1}^{n} K\left[\frac{\left(x-x_{i}\right)}{h}\right]
$$

Where $\mathrm{n}$ is the number of households, $\mathrm{h}$ is the bandwidth, and $\mathrm{K}$ is the kernel. The kernel function $\mathrm{K}$ and the bandwidth $\mathrm{h}$ are chosen with the efficiency bias tradeoff in mind. A larger bandwidth will generate a smoother estimate and reduce the variance but increase the bias.

To determine whether an increase in the price of food would be regressive or progressive, we use a non-parametric regression. This regression is the conditional expectation corresponding to the joint densities computed for expenditure and net benefit ratios and hence contains no new information. However, the regression does provide the answer to the question of by how much the people at each level of per capita expenditure would lose from the increase in the price of food. Since the net benefit ratio expresses the net benefit as a fraction of total household expenditure, a flat line would indicate that all rural households benefit proportionately, an upward sloping line that richer households benefit proportionately more and a downward sloping line that poor households benefit disproportionately. The kernel regression estimator can be written as follows:

$$
\hat{\beta}(x)=\sum_{i=1}^{n} y_{i} K\left[\frac{\left(x-x_{i}\right)}{h}\right] / \sum_{i=1}^{n} K\left[\frac{x-x_{i}}{h}\right]
$$

\section{Data}

Our household data is taken from two nationally representative surveys administered by Ethiopia's Central Statistical Authority during the period 1999/2000, the 
Welfare Monitoring Survey (WMS) and the Household Income, Consumption and Expenditure Survey (HICES). The WMS was introduced in 1994 with the explicit purpose of monitoring poverty in Ethiopia and is conducted every two years. The WMS 2000 covered 25,917 households and 123,735 individuals. The HICES, also introduced in 1994, covers a subset of the households surveyed in the WMS and collects more detailed information on consumption and expenditure by product by household than the WMS. One of the primary purposes of the HICES is to provide a basis for computing national accounts statistics. The HICES covered 17,332 households in 1999/2000.

Table 1 describes the size and structure of the two datasets employed to study whether or not households are net buyers or sellers of various crops. Both datasets employ standard clustered samples, derived from a two-stage sampling procedure. The first stage of sampling selected a random sample of small geographic units called enumeration areas (EAs), or neighborhoods of around 200 (100) households in urban (rural) areas. In the second stage, random samples of 12 to 35 households were selected from within each EA, as described in the table. The sample frame for both of these datasets excludes the non-sedentary populations concentrated in the regions of Afar and Somali. For details on sample design and data collection, see CSA (2001) and CSA (1999).

Ethiopia's sedentary population is about $14 \%$ urban and $86 \%$ rural (CSA 2001a). According to the CSA, urban includes the capitals of Regions, Zones and Weredas, any locality that is within an Urban Dweller's Association (or Kebele), any locality with 2000 or more residents, and any locality with 1000 or more residents whose residents are "primarily engaged in non-agricultural activities." Our merged dataset includes 8,212 urban and 8,308 rural households. Ethiopia is administratively divided into eleven regions, called Killils. Certain killils correspond with urban areas, such as Addis Ababa, Harari, and Dire Dawa. The other killils contain a combination of urban and rural areas.

Our measures of total expenditure are taken from the HICES. Because the version of the HICES that provides information on prices and quantities of crops purchased and 
sold is not yet available to the public, we use information from the WMS on total income and total expenditure by crop to compute net buyer status. The WMS includes two measures each for income and expenditure: for each cereal, it records the income in the past month, income in the past six months, expenditure in the past week, and expenditure in the past month. We use income in the past six months supplemented by income in the past month times six when income in the past six months is missing and expenditure in the past month times six supplemented by expenditure in the past week times 24 when expenditure in the past month is missing to measure net expenditure. Because the WMS covers only a subset of the HICES, we end up with a sample of 16,520 households after merging the two datasets.

To obtain measures of income and expenditure that can be meaningfully compared across households, we adjust for variations in regional prices and household composition. First, we deflate nominal values of income and expenditure by a regional price index computed by the CSA and reported in the "Poverty Profile of Ethiopia." (WMU, March 2002). Next, it is useful to recognize that the same total household expenditure may feed more (fewer) members of a family with relatively more (fewer) children (adults) and relatively more (fewer) women. Thus, we convert our measure of real household expenditure to a measure of real per capita expenditure on an adult equivalency basis using the East African adult equivalency scale developed by Dercon ${ }^{10}$.

The WMS 2000 was conducted from January to February, 2000. Therefore, the variable for six-month income covers the main harvesting season, which is September to December. Thus, the six-month income variable that we use to calculate net expenditure measures income from the latter half of the year and so includes the harvest months as well as the months immediately preceding the harvest, when cereals are least plentiful. Therefore, it is likely to be "representative" of annual cereals consumption. However, because the period of data collection immediately follows the harvest, the weekly and

\footnotetext{
${ }^{10}$ Thanks are due to Julie Schaffner for providing the adult equivalency scale and regional index programs for Stata. The adult equivalency scale is for East Africa and is based on a program provide by Stefan Dercon.
} 
monthly expenditure variables may overstate average cereals consumption. However, since prices of cereals are likely to be lower during this same period, this bias is likely to be minimal.

The HICES was conducted to capture the seasonality aspect of agriculture in Ethiopia. Each household was visited 8 times -4 times (once a week over the period of a month) during the rainy or lean season when stocks are low (June 11, 1999 - August 7, 1999) and then 4 times during the harvest period when stocks are plentiful (January 3, 2000 - February 26, 2000) ${ }^{11}$. Monthly totals for the two periods are then averaged to obtain monthly annual average household consumption expenditure and income.

Table 2 presents means of the main variables of interest. We use total real household expenditure per adult equivalent (rexpae) as our primary measure of household living standards. It is measured as total consumption expenditure per adult equivalent per year adjusted for regional variations in prices. Not surprisingly, judging by this standard, urban households enjoy a higher standard of living than rural households. In addition, there are marked variations across regions with Addis Ababa recording the highest rexpae of 2,232 birr and Tigray recording the lowest rexpae of 1,310 birr. Using the 1999 average nominal dollar birr exchange rate of 8.23, these translate into \$271 and \$159 respectively. The poorest regions in Ethiopia (Amhara, Oromiya, SNNPR and Tigray) also produce the majority of the nation's cereals. However, these regions are vast and agro-ecological conditions and hence poverty varies widely within the regions. Note also that the poorer regions tend to have larger households and that there appears to be no systematic variation in the age of household heads.

The second and third panels of Table 2 show the regional distribution of total real annual income and expenditure from the various cereals and coffee. We include coffee as a point of interest since it is widely consumed in Ethiopia and is Ethiopia's largest source of export earnings. For each crop, three items are reported: the mean across all

\footnotetext{
${ }^{11}$ There are two rainy seasons in Ethoipia. The main rainy season - meher - falls between May and September. The secondary rainy season - belg - falls between Feruary and May.
} 
households, the mean across only households who report receiving income from that crop and the percent of households reporting positive income from this crop. Based on these data, it appears that households tend to earn income from only one or two cereals, probably based on agro-ecological conditions. Looking at panel two, we see that rural households rely much more heavily on income from cereals than do urban households with $21 \%$ of rural households reporting positive income from teff, $12 \%$ from wheat, $10 \%$ from barley, 24\% from maize, $11 \%$ from sorghum and $12 \%$ from coffee. For urban households, these same figures are $2 \%, 1 \%, .6 \%, 3 \% 1 \%$ and $.8 \%$ respectively.

Panel three presents information on total real expenditure per household. On average, expenditures exceed income for all crops and a much larger share of the population reports positive expenditures on the various crops with more than half reporting that they spent some money on teff, for example. There is a marked difference between urban and rural with a much larger percent of the urban population (76\%) reporting expenditure on the most expensive cereal, teff, than the rural population (33\%). The most widely consumed cereals in the rural sector are maize (57\%), sorghum (40\%), teff (33\%), wheat (32\%) and barley (22\%). The most widely consumed cereals in the urban sector are teff (76\%), wheat (39\%), maize (28\%), sorghum (22\%) and barley $(14 \%)$.

Panel 4 presents data on budget shares for all households and then only for those households who report spending anything on that particular item. These figures indicate that households spend a large fraction of their annual income on cereals ranging from $26 \%$ to $12 \%$ for rural households and $16 \%$ to $5 \%$ for urban households. Thus, changes in cereals prices can have substantial welfare effects and reduction in cereals prices is likely to transfer real income from urban households to rural households. Only $12 \%$ of rural households in the survey received any income from wheat, the only cereal imported in the form of food aid, and it is these households that stand to gain from an increase in the price of wheat. 
The fact that mean expenditures on cereals exceed mean income from cereals naturally leads to the following question - what are the other sources of income in Ethiopia? Also using these data, Peacemaker-Arrand (2004) reports that rural respondents predominantly describe themselves as subsistence farmers, with $87 \%$ reporting that the households' main source of income is subsistence farming. Interestingly, she finds that the most widespread source of income among these rural households is livestock. Only $4.1 \%$ of rural households support themselves with formal employment, while $2.4 \%$ rely on "casual labor." Moreover, the picture is very different in urban areas where the majority of households' report main income source as formal employment, while an additional $10 \%$ rely on casual labor. Interestingly, she also finds that urban residents rely more on pensions, rent and family remittances than rural households.

Our data on food aid come from the World Food Programme (WFP) and Ethiopia's Disaster Preparedness and Prevention Centre (DPPC). Table 3 presents cereals production and cereals food aid from 1995 to 2001. Several facts are worth noting. First, virtually all imported cereals food aid comes in the form of wheat. Second, though the US provides a substantial share of the wheat food aid (42.5\% in 1999), the majority of the imported wheat comes from a variety of other donors, mostly European. This is notable because of the European's tendency to blame these phenomenons on the U.S. Third, although some food aid is purchased locally, the majority of food aid is imported and the majority of food aid is wheat. Over the period 1995-2001, an average of $20 \%$ of cereals food aid was purchased locally. Locally purchased food aid consists primarily of wheat, maize and sorghum and accounts for a tiny fraction of the total production of each of these commodities. By contrast, 663 thousand tonnes of wheat food aid were imported in 1999 while only 1,114 tonnes were produced locally. Thus, wheat food aid accounted for more than a third of the total supply of wheat and potentially had a significant effect on the price of wheat.

\section{Who Benefits from Food Aid?}

Since all imported cereals food aid is wheat, we now restrict our attention to the impact of an increase in the price of wheat that would likely result if there were no food 
aid. The averages reported in Table 2 do not tell us anything about production and consumption patterns of wheat according to income level. We are specifically interested in the impact of changes in the price of wheat on the poor, thus, we need to know whether the poor earn more or less income from wheat than rich households. We would also like to know whether they spend more or less on wheat than rich households. In what follows, we examine the living standards of buyers and sellers of wheat. We also examine who is most likely to benefit in proportional terms from a reduction in wheat prices.

Figures 1 through 3 show estimates of the distribution of real per adult equivalent expenditure across households that are net buyers of wheat and across households that are net sellers of wheat. Since the distribution for the entire population is almost identical to the distribution of net buyers, we do not overlay this density function on Figures 1 through three. Rather, the densities for the entire population are presented in Appendix 1. Figure 1 is the distribution for the entire population, Figure 2 is the distribution for the rural population and Figure 3 is the distribution for the urban population. All three graphs show the estimated density functions of the logarithm of household per adult equivalent expenditure by whether a household is classified as a net seller or buyer of wheat. The $\log$ transformation is chosen because the distribution of expenditure per capita is strongly positively skewed and taking logs introduces something closer to symmetry.

The most striking feature of Figure 1 is the similarity of the two distributions. The modal net seller is only slightly wealthier than the modal net buyer: modal expenditure per capita per adult equivalent of the net buyer is 1,096 Birr $(\$ 134)^{12}$ compared to 1,211 Birr (\$148) for net sellers. Though the patterns are similar, the differences are slightly more pronounced once the sample is split into urban and rural. Figure 2 shows that for rural households, modal expenditure per capita per adult equivalent of the net buyer is 1,096 Birr (\$134) compared to 1,339 Birr (\$163) for net sellers. Figure 3 shows that the differences are most pronounced for urban households where the modal expenditure per capita per adult equivalent of the net buyer is 1,212 Birr (\$148) compared to 2,981 Birr (\$364) for net sellers. Figures 2 and 3 confirm the fact that urban households tend to

\footnotetext{
${ }^{12}$ All dollar figures are obtained using the nominal average exchange rate of 8.2 Birr per USD in 1999.
} 
enjoy a higher standard of living and that there is more diversity among the urban population.

Figures 4-11 show results of non-parametric regressions of buyers and sellers of wheat by expenditure category. Each graph contains two lines. The line that is connected by squares shows the proportion of households out of all households that report spending any money on wheat. The line that is connected by diamonds shows the proportion of households out of all households that report earning any income from selling wheat. These are the results of two separate non-parametric regressions where the dependent variable takes a value of one if the household reports purchasing (selling) any wheat and zero otherwise and the explanatory variable is expenditure per adult equivalent divided into thirty quantiles. The bottom third of the expenditure per adult equivalent distribution ranges between 1,113 Birr (\$136) and 2,302 Birr (\$281), the middle third of the distribution ranges between 2,417 Birr (\$295) and 3,718 Birr (\$453). The top third of the distribution ranges between 3,933 Birr (\$480) and 10,762 (\$1,312). For each quantile, these graphs tell us the proportion of households that report spending any money on wheat and the proportion of households that report purchasing any wheat. The graphs provide more detail on the structure of our data. In Figure 4, we report this information for the entire country. We then present results for rural and urban populations and for several regions separately.

All eight figures show that at all levels of income, there are more buyers than sellers of wheat. This is important because it means that at all levels of living standards, more households will benefit from food aid (a reduction in wheat prices) than will be hurt. This is consistent with the fact that Ethiopia is a net importer of food. However, even though Ethiopia is a net food importer, it is not the case that among the poor, the majority of households are net sellers of food. Thus, it is not the case that food imports benefit only the relatively better off urban population.

For the population as a whole, the proportion of households that sells wheat hovers around $10 \%$ until it drops sharply at the very highest levels of income. The 
proportion of households that purchase wheat tends to increase with income starting at around $25 \%$ and tapering off at around $35 \%$ until it too falls - though less sharply - at the very highest levels of income.

Figure 5 shows that among the rural population, the proportion of households that sell wheat is increasing in income. The proportion of households that buys wheat is also increasing in income and goes from around $20 \%$ for the poorest households to almost $40 \%$ for the wealthiest households. Figure 6 shows that among urban households, there is no significant relationship between living standards and the proportion of buyers and sellers of wheat - except at the very highest levels of income where both taper off. A comparison between figures 5 and 6 yields some interesting insights. There is much more diversity among rural households and - at all levels of income - more rural households are engaged in selling wheat than are urban households.

Figures 7 through 11 confirm that the importance of wheat also varies by region. Figure 7 confirms the statistics in Table 2 which suggest that wheat is most important in Tigray where more than $11 \%$ of households report earning income from wheat and $49 \%$ of households report spending any money on wheat. Interestingly, Tigray is also the poorest region and the region from which most of the current government originates. The pattern of income in Tigray appears to be slightly different from the pattern for the rest of the country. The proportion of households reporting income from wheat increases with income and then begins to taper off after the tenth quantile suggesting that more poorer households in Tigray rely on wheat as a source of income than do richer households though the differences are not large (20\% vs. $15 \%)$. On the income side, the pattern is similar, with one interesting difference: even among the very poorest households roughly $40 \%$ spend money on wheat. This compares with between 10 and $30 \%$ for the remaining regions and $20 \%$ for the country as a whole. Thus, Tigray is the region most likely to be affected by changes in wheat prices.

The next step is to combine the information on income and expenditure of wheat and to examine net sellers of wheat by expenditure category. Net sellers of wheat are the 
households that would be hurt by the reduction in wheat prices associated with food aid. Figure 12 presents these results for the entire population while Figure 13 presents results for the rural population and Figure 14 for the urban population. These figures are results of a non-parametric regression where the dependent variable takes a value of one if the household is a net seller and zero otherwise and the explanatory variable is expenditure quantiles. The shape of the line in Figure 12 is clearly driven by the households in the upper tail of the expenditure categories, so we turn immediately to Figures 13 and 14 which are easier to interpret. Figure 13 shows that there is a positive relationship between whether or not a household is a net seller of wheat and living standards. Among the rural population, contrary to popular wisdom, there are more net sellers of wheat among the richer households and the relationship is close to linear. Figure 13 also makes it clear that roughly $85 \%$ of the poorest households are net buyers of wheat. Figure 14 shows that net seller status among urban households is also increasing in income for the first two terciles of the distribution. Among the wealthiest urban households net sellers of wheat drop off quickly. Not surprisingly, a comparison of Figures 13 and 14 show that at all levels of income, there are proportionately more net sellers among the rural population.

Figures 15-17 show results of regressions of the net benefit ratio on quantiles of per adult equivalent expenditure ${ }^{13}$. The net benefit ratio is defined as total household expenditure on wheat per year less total household income from wheat per year divided by total household expenditure per year. Thus, a ratio greater than zero indicates that the household is a net buyer of wheat and expresses the household's deficit as a fraction of total household expenditure. These figures show by how much Ethiopians at each level of living would benefit from a reduction in the price of wheat. Since the ratio expresses the net benefit as fraction of total household consumption, a flat line would show that all rural households benefit proportionately, thus, the change is neither regressive nor progressive. Our data show that a reduction in the price of wheat would benefit poor households disproportionately and hence be progressive. This is true for the population as a whole (Figure 15), for the rural population (Figure 16) and for the urban population

\footnotetext{
${ }^{13}$ Note that these figures exclude households who report both zero income from wheat and zero expenditure on wheat.
} 
(Figure 17). These figures also suggest that the magnitude of the deficit as a share of total expenditure is fairly large for the poorest households (slightly higher than $8 \%$ ) close to insignificant for the richest households (between 1 and 2\%).

In summary, our analysis indicates that (i) net buyers of wheat are poorer than net sellers of wheat, (ii) there are more buyers of wheat than sellers of wheat at all levels of income, (iii) the proportion of net sellers is increasing in living standards and (iv) net benefit ratios are higher for poorer households indicating that poorer households benefit proportionately more from a drop in the price of rice. In light of this evidence, it appears that the average household at all levels of income benefits from food aid and that somewhat surprisingly - the benefits go disproportionately to the poorest households. Several caveats must be kept in mind. First, even the non-parametric regressions are averages by income category and so could mask underlying trends. The extent to which these averages reflect the true effects of price changes on poverty depend on whether these averages truly represent the typical household, or whether there is a significant amount of variation among poor households even at the poorest income levels. Second, we have not considered dynamic effects. It is possible that higher wheat prices could increase the incentive to invest in agriculture and eventually lead to lower wheat prices.

We have established that food aid is likely to help the poor disproportionately. We have also established that for the poorest households, the deficit is large at around $8 \%$ and so the overall impact of food aid on household welfare can have a substantial impact on the poorest households. What we still do not know is whether food aid has a significant impact on prices. We turn now to this issue.

\section{Does Food Aid Depress Wheat Prices?}

To answer this question, we use the supply/demand framework presented in Figure 18. For simplicity, we assume constant-elasticity demand and supply functions,

$$
\mathrm{D}=\mathrm{k}_{0} \mathrm{P}^{-\varepsilon} \quad \text { and } \mathrm{S}=\mathrm{k}_{1} \mathrm{P}^{v}
$$


where $\mathrm{k}_{0}$ and $\mathrm{k}_{1}$ are parameters, $\mathrm{P}$ is the market price of wheat, and $\varepsilon$ and $\mathrm{v}$ are demand and supply elasticities, respectively. Our estimate of $\mathrm{P}$ is a production weighted regional average of wheat producer prices for 1999. Our estimate of the elasticity of supply is 0.45 and is based on Soledad Bos (2002). Our estimate of the elasticity of demand is based on Regmi et al (2001), who found that low-income countries have own-price elasticities of demand for cereals of about -.6. Using these estimates and the observed quantities of wheat produced and consumed in Ethiopia, we are able to calibrate the model. The resulting supply and demand for wheat in Ethiopia are given by,

$$
\mathrm{D}=41,325 \mathrm{P}^{-.6} \text { and } \mathrm{S}=104 \mathrm{P}^{.45}
$$

Using these estimates of the supply and demand functions, we find that the price of wheat would be $\$ 295$ per metric tonne in the absence of food aid compared with an average observed price of $\$ 193$ per metric tonne in 1999. We also find that the price increase would lead to an increase in producer surplus of around 125 million US dollars and a reduction in consumer surplus of around 159 million US dollars. Overall, the increase in the price of wheat leads to a net welfare loss of approximately 34 million US dollars. There were roughly 12 million households in Ethiopia in 1999 of which 4.3 million reported spending money on wheat and .8 million reported earning income from wheat. Therefore, on average, the loss in consumer surplus works out to roughly 37 US dollars per household per year for households that consume wheat and the gain in producer surplus works out to roughly 157 US dollars per household per year for households that sell wheat. In Ethiopia, where the poverty line is roughly 1057 Birr (\$132), these effects are quite large.

\section{Conclusions}

The argument against developed countries' agricultural subsidies is largely motivated by a desire to improve the living standards of the world's rural poor. Yet, for countries like Ethiopia that are net food importers, a rise in food prices leads to a net welfare loss. This might be acceptable if, in the process, real income were being 
transferred from the relatively better off urban population to the rural poor. However, our analysis suggests that this is not the case. Although households at all levels of living standards benefit from a reduction in food prices, the benefits are proportionately larger for the poorest households. Rough estimates of the welfare impact of the price changes associated with food aid suggest that the impacts on net sellers and net buyers of these price changes is substantial.

Because of the magnitude of the average welfare effects per household, we believe that this issue warrants further attention. In particular, it will be important in future work to confirm that prices in remote areas follow the same pattern as prices in major retail centers. To understand better where the price effects of food aid are being felt and how the magnitude of these effects varies across locations, it will also be important to compare food aid deliveries to local production by region or wereda. A somewhat more difficult issue has to do with the timing of food aid deliveries. If food aid is not delivered in a timely manner, it could aggravate the cyclicality of prices associated with the harvesting and lean seasons due to inadequate storage. The most difficult issue has to do with the disincentive effects of food aid. Again, given the magnitude of the price changes associated with food aid and the associated per household welfare implications, this seems like an issue worth exploring. 
Table 1: Data Structure

\begin{tabular}{|c|c|c|c|c|c|c|c|c|c|}
\hline \multicolumn{5}{|c|}{ Welfare Monitoring Survey 2000} & \multicolumn{5}{|c|}{$\begin{array}{c}\text { 1999/2000 Household Income, Consumption and Expenditure } \\
\text { Survey }\end{array}$} \\
\hline $\begin{array}{l}\text { Regional } \\
\text { States }\end{array}$ & & -Rural & -Urban & Total & $\begin{array}{l}\text { Regional } \\
\text { States }\end{array}$ & & -Rural & -Urban & Total \\
\hline \multirow[t]{2}{*}{ Tigray } & Sample EAs & 100 & 43 & 143 & 3 Tigray & Sample EAs & & & 90 \\
\hline & Sample households & 1196 & 687 & 1883 & & Sample households & & & 1252 \\
\hline \multirow[t]{2}{*}{ Affar } & Sample EAs & 59 & 25 & 84 & 4 Affar & Sample EAs & & & 58 \\
\hline & Sample households & 699 & 400 & 1099 & & Sample households & & & 792 \\
\hline \multirow[t]{2}{*}{ Amhara } & Sample EAs & 283 & 100 & 383 & Amhara & Sample EAs & & & 245 \\
\hline & Sample households & 3393 & 1593 & 4986 & & Sample households & & & 3340 \\
\hline \multirow[t]{2}{*}{ Oromia } & Sample EAs & 360 & 119 & 479 & 9 Oromia & Sample EAs & & & 271 \\
\hline & Sample households & 4318 & 1903 & 6221 & & Sample households & & & 3728 \\
\hline \multirow[t]{2}{*}{ Somalia } & Sample EAs & 56 & 30 & 86 & Somalia & Sample EAs & & & 61 \\
\hline & Sample households & 672 & 480 & 1152 & & Sample households & & & 852 \\
\hline \multirow[t]{2}{*}{$\begin{array}{l}\text { Benshangul } \\
\text { Gumuz }\end{array}$} & Sample EAs & 75 & 25 & 100 & $\begin{array}{l}\text { Benshangul } \\
\text { Gumuz }\end{array}$ & Sample EAs & & & 68 \\
\hline & Sample households & 900 & 400 & 1300 & & Sample households & & & 916 \\
\hline \multirow[t]{2}{*}{ SNNP } & Sample EAs & 394 & 48 & 442 & 2 SNNP & Sample EAs & & & 204 \\
\hline & Sample households & 4727 & 768 & 5495 & & Sample households & & & 2640 \\
\hline \multirow[t]{2}{*}{ Gambela } & Sample EAs & 30 & 24 & 54 & 4 Gambela & Sample EAs & & & 54 \\
\hline & Sample households & 360 & 383 & 743 & & Sample households & & & 744 \\
\hline \multirow[t]{2}{*}{ Harari } & Sample EAs & 30 & 23 & 53 & 3 Harari & Sample EAs & & & 53 \\
\hline & Sample households & 360 & 368 & 728 & & Sample households & & & 728 \\
\hline \multirow[t]{2}{*}{ Addis Ababa } & Sample EAs & 25 & 75 & 100 & Addis Ababa & Sample EAs & & & 100 \\
\hline & Sample households & 300 & 1181 & 1481 & & Sample households & & & 1500 \\
\hline \multirow[t]{2}{*}{$\begin{array}{l}\text { Dire Dawa } \\
\text { Adm. council }\end{array}$} & Sample EAs & 30 & 30 & & \begin{tabular}{|l} 
Dire Dawa \\
Adm. council
\end{tabular} & Sample EAs & & & 60 \\
\hline & Sample households & 360 & 480 & 840 & & Sample households & & & 840 \\
\hline \multirow[t]{2}{*}{ Grand Total } & Sample EAs & 1442 & 542 & 1984 & 4 Grand Total & Sample EAs & 722 & 542 & 1264 \\
\hline & Sample households & 17285 & 8643 & 25928 & & Sample households & 8660 & 8672 & 17332 \\
\hline
\end{tabular}


Table 2: Means of Variables Used in Analysis

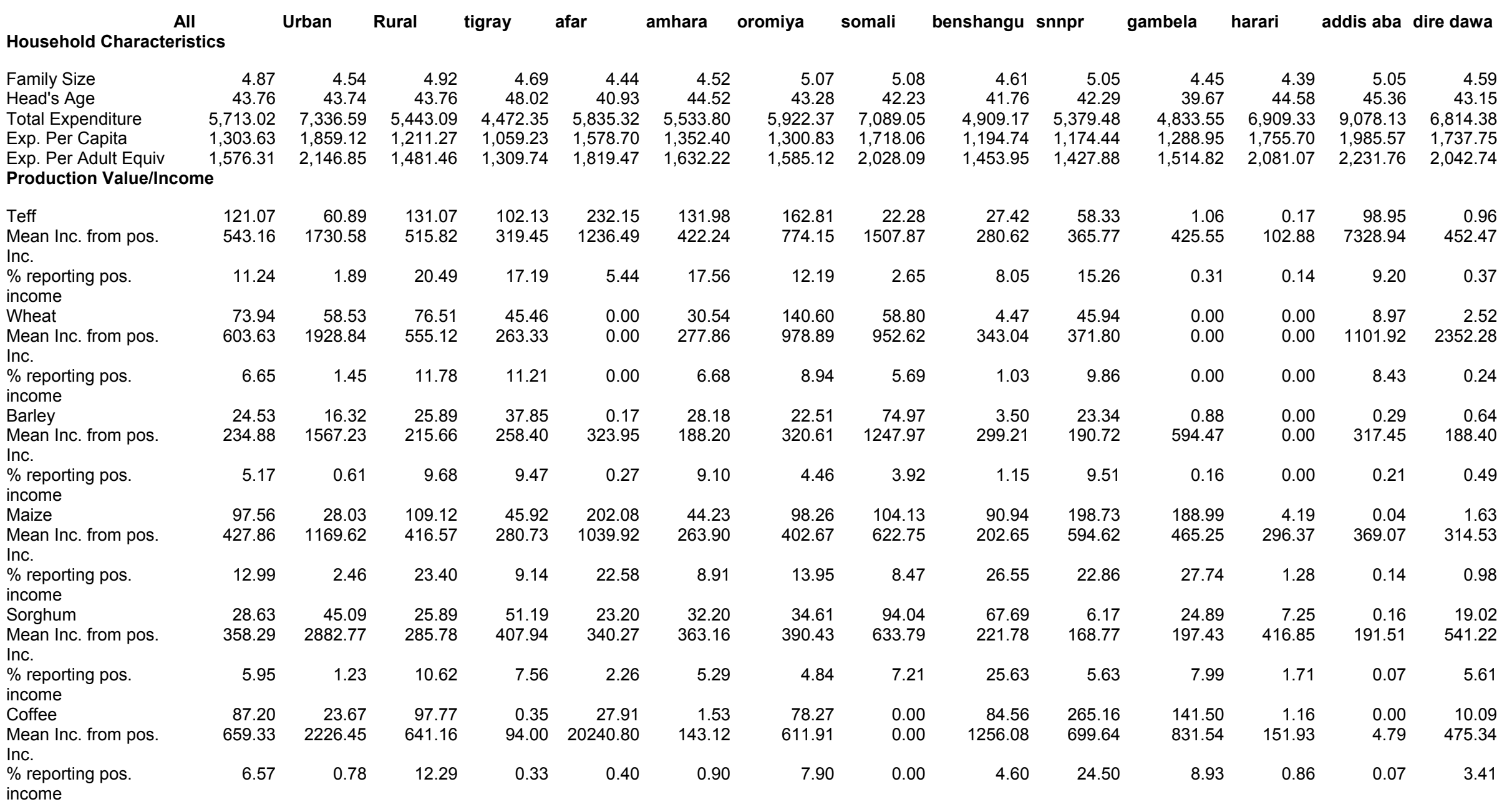




\begin{tabular}{|c|c|c|c|c|c|c|c|c|c|c|c|c|c|c|}
\hline Expenditures & & Urban & Rural & tigray & far & amhara & oromiya & somali & benshangu & snnpr & gambela & harari & addis aba & dire dawa \\
\hline Teff & 542.44 & 774.89 & 503.79 & 1065.33 & 673.40 & 959.39 & 370.24 & 167.73 & 161.98 & 104.65 & 167.79 & 362.21 & 966.74 & 377.82 \\
\hline $\begin{array}{l}\text { Mean exp. from pos. } \\
\text { exp. }\end{array}$ & 1231.02 & 1014.60 & 1302.05 & 2075.05 & 1152.23 & 1529.50 & 879.72 & 1240.76 & 561.05 & 624.58 & 953.42 & 811.33 & 1167.74 & 852.15 \\
\hline $\begin{array}{l}\text { \% reporting pos. } \\
\text { exp. }\end{array}$ & 54.56 & 76.36 & 33.02 & 61.96 & 51.00 & 73.76 & 59.82 & 25.54 & 42.07 & 33.85 & 31.66 & 39.09 & 85.02 & 35.24 \\
\hline Wheat & 206.47 & 173.24 & 211.99 & 292.28 & 38.13 & 232.35 & 237.98 & 329.55 & 16.04 & 119.09 & 40.96 & 271.30 & 112.77 & 78.21 \\
\hline $\begin{array}{l}\text { Mean exp. from pos. } \\
\text { exp. }\end{array}$ & 624.13 & 405.70 & 673.40 & 660.99 & 384.26 & 718.05 & 625.73 & 645.66 & 300.09 & 481.52 & 416.77 & 598.27 & 427.46 & 398.07 \\
\hline $\begin{array}{l}\% \text { reporting pos. } \\
\text { exp. }\end{array}$ & 35.65 & 39.10 & 32.25 & 49.09 & 13.15 & 30.15 & 46.70 & 52.72 & 14.02 & 36.10 & 12.70 & 48.50 & 34.56 & 22.32 \\
\hline Barley & 123.82 & 44.34 & 137.04 & 217.58 & 27.01 & 189.64 & 110.11 & 46.25 & 9.57 & 67.17 & 7.30 & 19.32 & 13.23 & 19.75 \\
\hline $\begin{array}{l}\text { Mean exp. from pos. } \\
\text { exp. }\end{array}$ & 512.60 & 295.45 & 533.71 & 638.18 & 319.20 & 648.28 & 461.37 & 323.45 & 244.48 & 320.75 & 391.90 & 196.91 & 338.28 & 212.27 \\
\hline $\begin{array}{l}\% \text { reporting pos. } \\
\text { exp. }\end{array}$ & 17.72 & 13.92 & 21.47 & 24.09 & 7.44 & 19.75 & 25.07 & 15.68 & 4.37 & 27.21 & 2.04 & 9.27 & 4.11 & 7.07 \\
\hline Maize & 289.11 & 116.70 & 317.78 & 233.82 & 481.52 & 171.05 & 352.61 & 562.67 & 299.04 & 380.07 & 522.29 & 163.58 & 25.34 & 87.22 \\
\hline $\begin{array}{l}\text { Mean exp. from pos. } \\
\text { exp. }\end{array}$ & 565.45 & 380.37 & 582.77 & 641.17 & 890.64 & 515.37 & 608.15 & 776.36 & 428.20 & 518.90 & 759.88 & 518.17 & 309.56 & 691.78 \\
\hline $\begin{array}{l}\text { \% reporting pos. } \\
\text { exp. }\end{array}$ & 42.26 & 27.83 & 56.54 & 24.92 & 61.75 & 22.50 & 52.23 & 45.13 & 56.78 & 70.26 & 65.67 & 37.09 & 9.48 & 17.80 \\
\hline Sorghum & 189.24 & 70.91 & 208.92 & 262.55 & 210.08 & 234.85 & 211.03 & 231.55 & 286.35 & 78.70 & 184.85 & 492.89 & 4.91 & 510.12 \\
\hline $\begin{array}{l}\text { Mean exp. from pos. } \\
\text { exp. }\end{array}$ & 609.07 & 341.83 & 637.21 & 698.62 & 695.64 & 778.62 & 557.35 & 705.92 & 469.54 & 391.48 & 499.48 & 768.37 & 165.09 & 890.60 \\
\hline $\begin{array}{l}\% \text { reporting pos. } \\
\text { exp. }\end{array}$ & 30.79 & 21.51 & 39.97 & 28.41 & 13.94 & 22.79 & 30.65 & 30.34 & 71.61 & 26.71 & 31.50 & 68.05 & 2.79 & 67.20 \\
\hline Coffee & 144.58 & 152.45 & 143.28 & 117.44 & 150.66 & 111.67 & 146.36 & 154.00 & 144.07 & 195.78 & 104.10 & 93.00 & 139.40 & 105.65 \\
\hline $\begin{array}{l}\text { Mean exp. from pos. } \\
\text { exp. }\end{array}$ & 168.48 & 169.27 & 168.34 & 148.73 & 191.73 & 127.63 & 173.75 & 170.59 & 164.99 & 222.15 & 178.50 & 131.10 & 152.49 & 131.60 \\
\hline $\begin{array}{l}\text { \% reporting pos. } \\
\text { exp. } \\
\text { Budget Shares }\end{array}$ & 85.40 & 90.12 & 80.73 & 83.64 & 80.35 & 87.28 & 89.19 & 90.77 & 91.38 & 85.33 & 63.64 & 67.76 & 92.96 & 76.22 \\
\hline Teff & 0.10 & 0.12 & 0.10 & 0.28 & 0.15 & 0.18 & 0.06 & 0.02 & 0.03 & 0.02 & 0.03 & 0.06 & 0.14 & 0.06 \\
\hline $\begin{array}{l}\text { Mean exp. from pos. } \\
\text { exp. }\end{array}$ & 0.24 & 0.16 & 0.26 & 0.54 & 0.26 & 0.29 & 0.15 & 0.15 & 0.09 & 0.11 & 0.16 & 0.13 & 0.17 & 0.13 \\
\hline Wheat & 0.04 & 0.03 & 0.04 & 0.07 & 0.01 & 0.05 & 0.04 & 0.05 & 0.00 & 0.02 & 0.01 & 0.04 & 0.02 & 0.01 \\
\hline $\begin{array}{l}\text { Mean exp. from pos. } \\
\text { exp. }\end{array}$ & 0.12 & 0.07 & 0.13 & 0.17 & 0.09 & 0.15 & 0.11 & 0.10 & 0.04 & 0.09 & 0.09 & 0.08 & 0.06 & 0.07 \\
\hline Barley & 0.03 & 0.01 & 0.03 & 0.06 & 0.01 & 0.04 & 0.02 & 0.01 & 0.00 & 0.01 & 0.00 & 0.00 & 0.00 & 0.00 \\
\hline $\begin{array}{l}\text { Mean exp. from pos. } \\
\text { exp. }\end{array}$ & 0.11 & 0.05 & 0.12 & 0.17 & 0.08 & 0.14 & 0.10 & 0.06 & 0.03 & 0.07 & 0.09 & 0.03 & 0.04 & 0.03 \\
\hline Maize & 0.06 & 0.03 & 0.07 & 0.06 & 0.12 & 0.04 & 0.07 & 0.10 & 0.08 & 0.08 & 0.12 & 0.03 & 0.01 & 0.01 \\
\hline $\begin{array}{l}\text { Mean exp. from pos. } \\
\text { exp. }\end{array}$ & 0.12 & 0.08 & 0.12 & 0.16 & 0.22 & 0.12 & 0.12 & 0.13 & 0.11 & 0.11 & 0.18 & 0.08 & 0.08 & 0.12 \\
\hline Sorghum & 0.04 & 0.02 & 0.04 & 0.07 & 0.06 & 0.05 & 0.04 & 0.05 & 0.07 & 0.02 & 0.04 & 0.08 & 0.00 & 0.09 \\
\hline $\begin{array}{l}\text { Mean exp. from pos. } \\
\text { exp. }\end{array}$ & 0.13 & 0.08 & 0.13 & 0.19 & 0.20 & 0.16 & 0.11 & 0.14 & 0.12 & 0.10 & 0.12 & 0.12 & 0.03 & 0.15 \\
\hline Coffee & 0.03 & 0.03 & 0.03 & 0.03 & 0.03 & 0.02 & 0.03 & 0.02 & 0.03 & 0.04 & 0.02 & 0.02 & 0.02 & 0.02 \\
\hline $\begin{array}{l}\text { Mean exp. from pos. } \\
\text { exp. }\end{array}$ & 0.03 & 0.03 & 0.04 & 0.04 & 0.04 & 0.03 & 0.03 & 0.03 & 0.04 & 0.05 & 0.04 & 0.02 & 0.03 & 0.02 \\
\hline
\end{tabular}




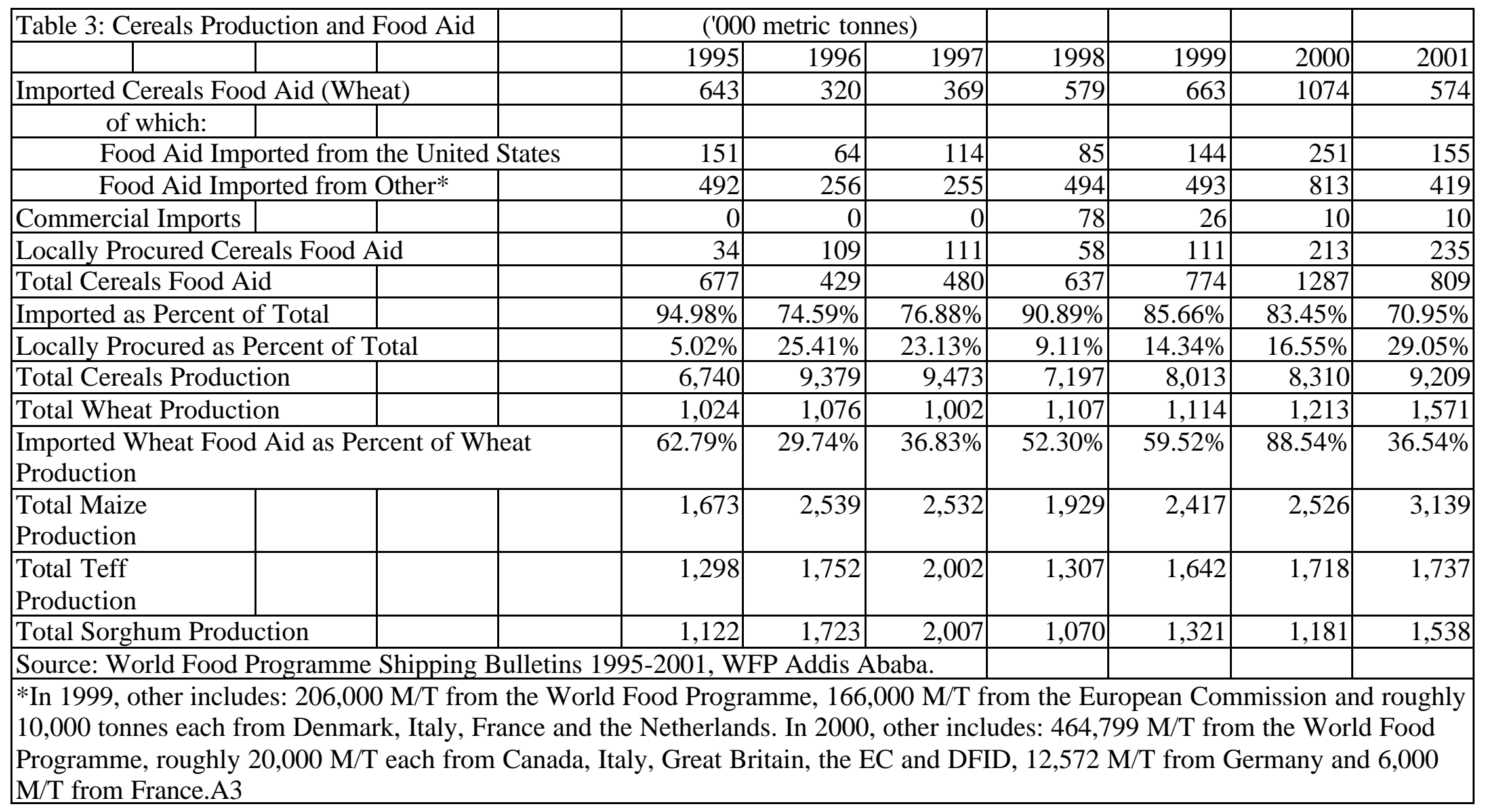


Figure 1 : Living Standard of Net Buyers and Sellers of Wheat - Entire Population

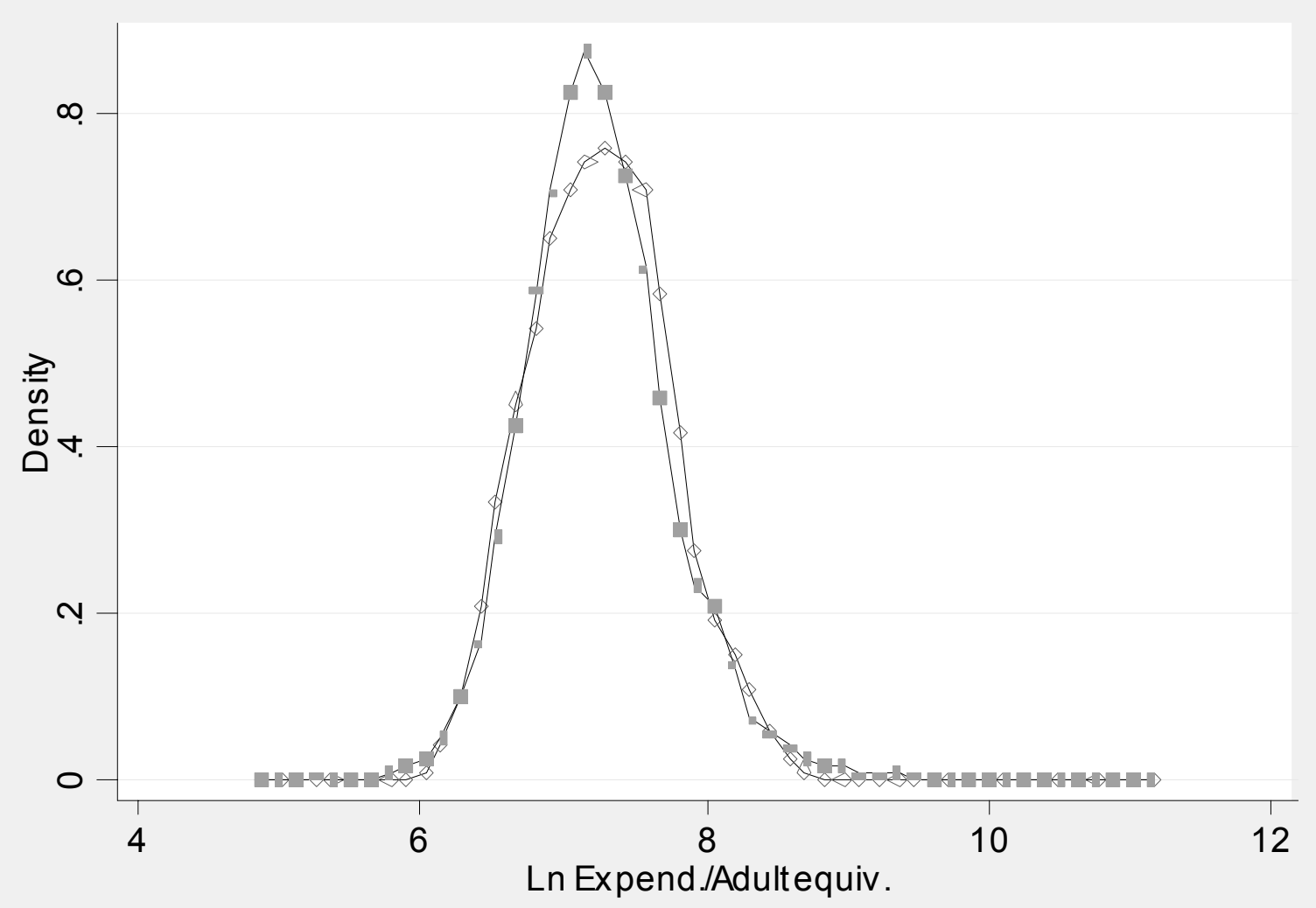

NetSellers Wheat —— NetBuyers Wheat 
Figure 2 : Living Standard of Net Buyers and Sellers of Wheat - Rural Population

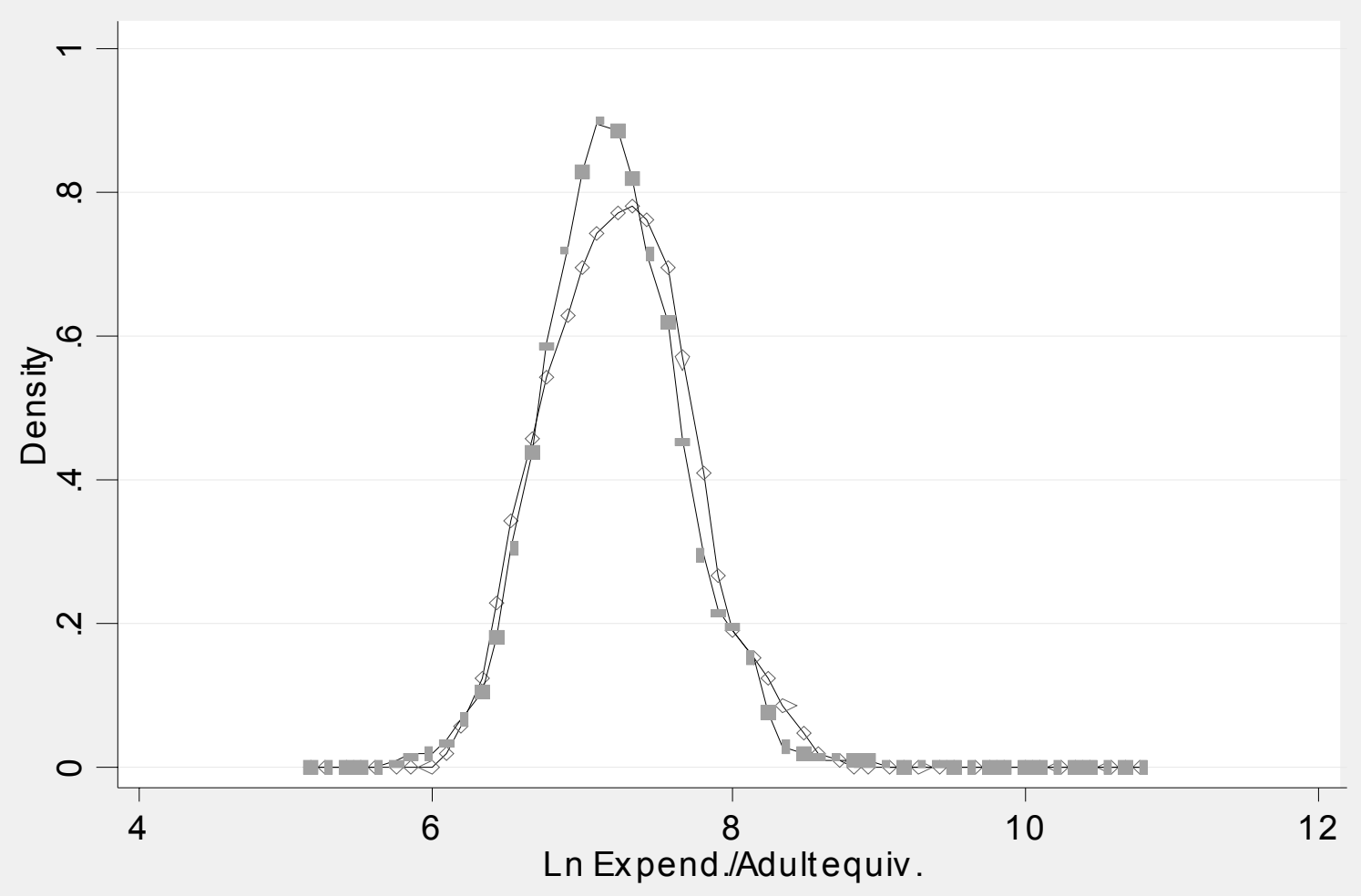


Figure 3 : Living Standard of Net Buyers and Sellers of Wheat - Urban Population

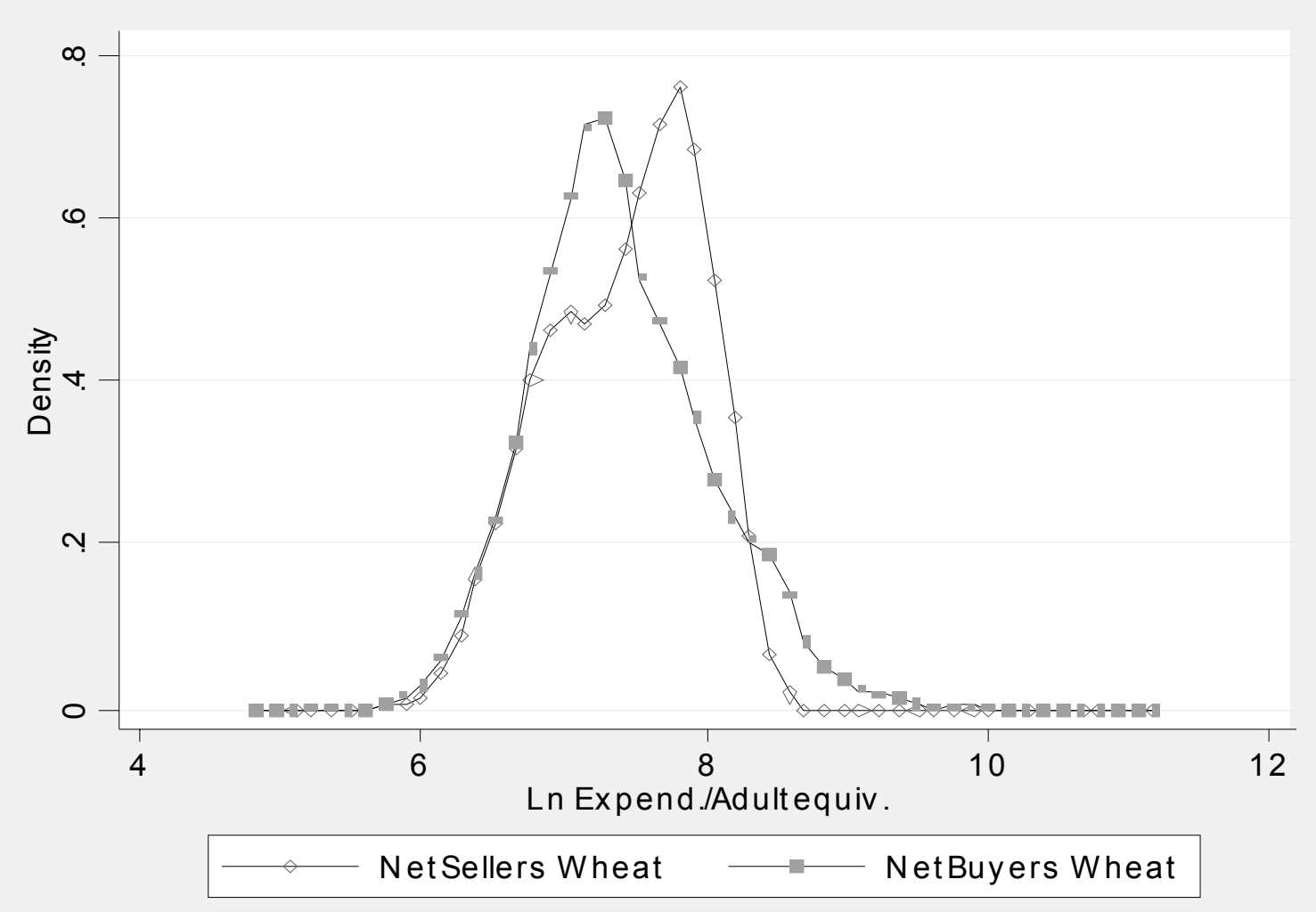


Figure 4: Buyers and Sellers of Wheat by Expenditure Category - Entire Country (with fitted values based on nonparametric regression)

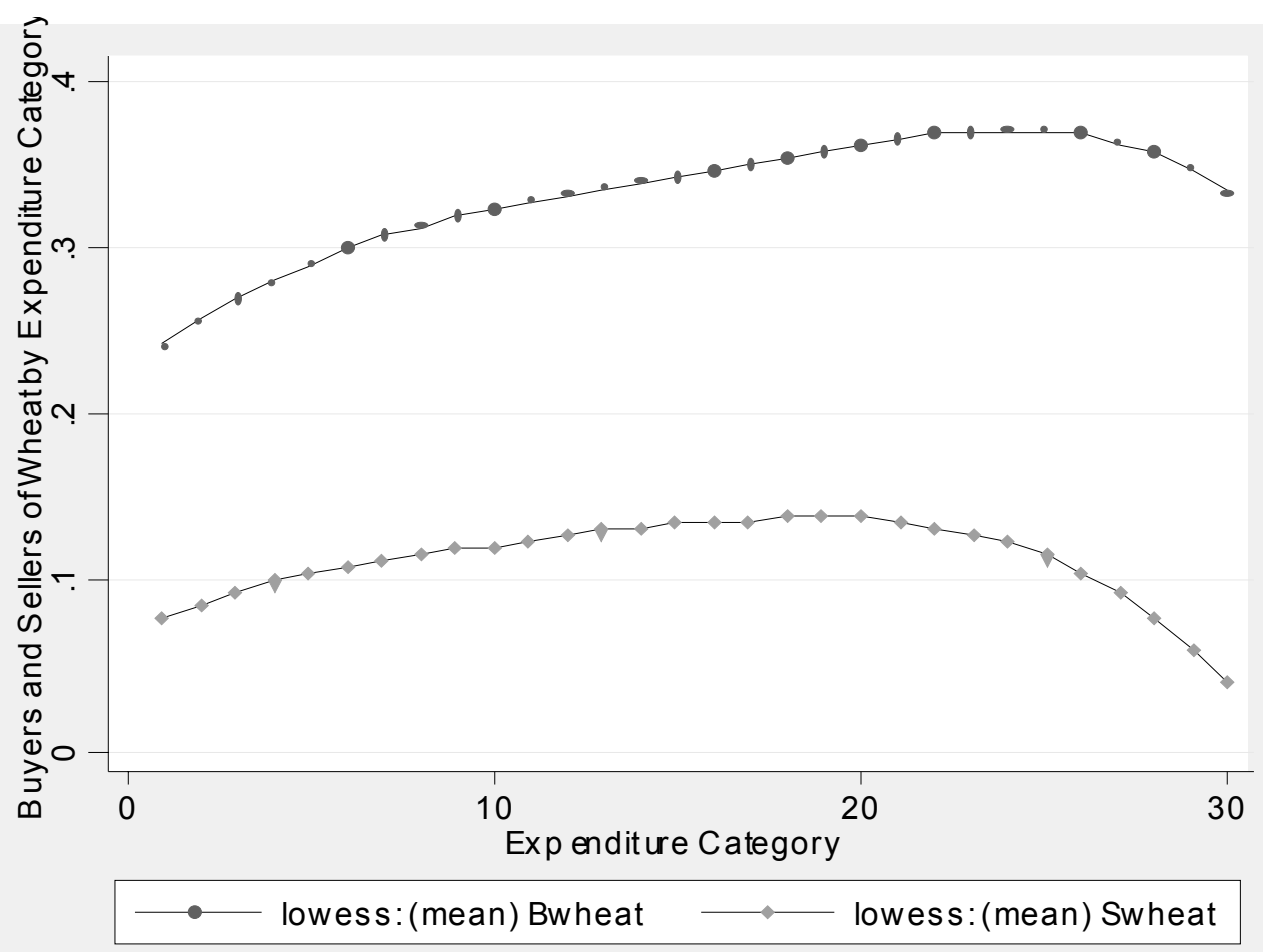


Figure 5: Buyers and Sellers of Wheat by Expenditure Category - Rural Population (with fitted values based on nonparametric regression)

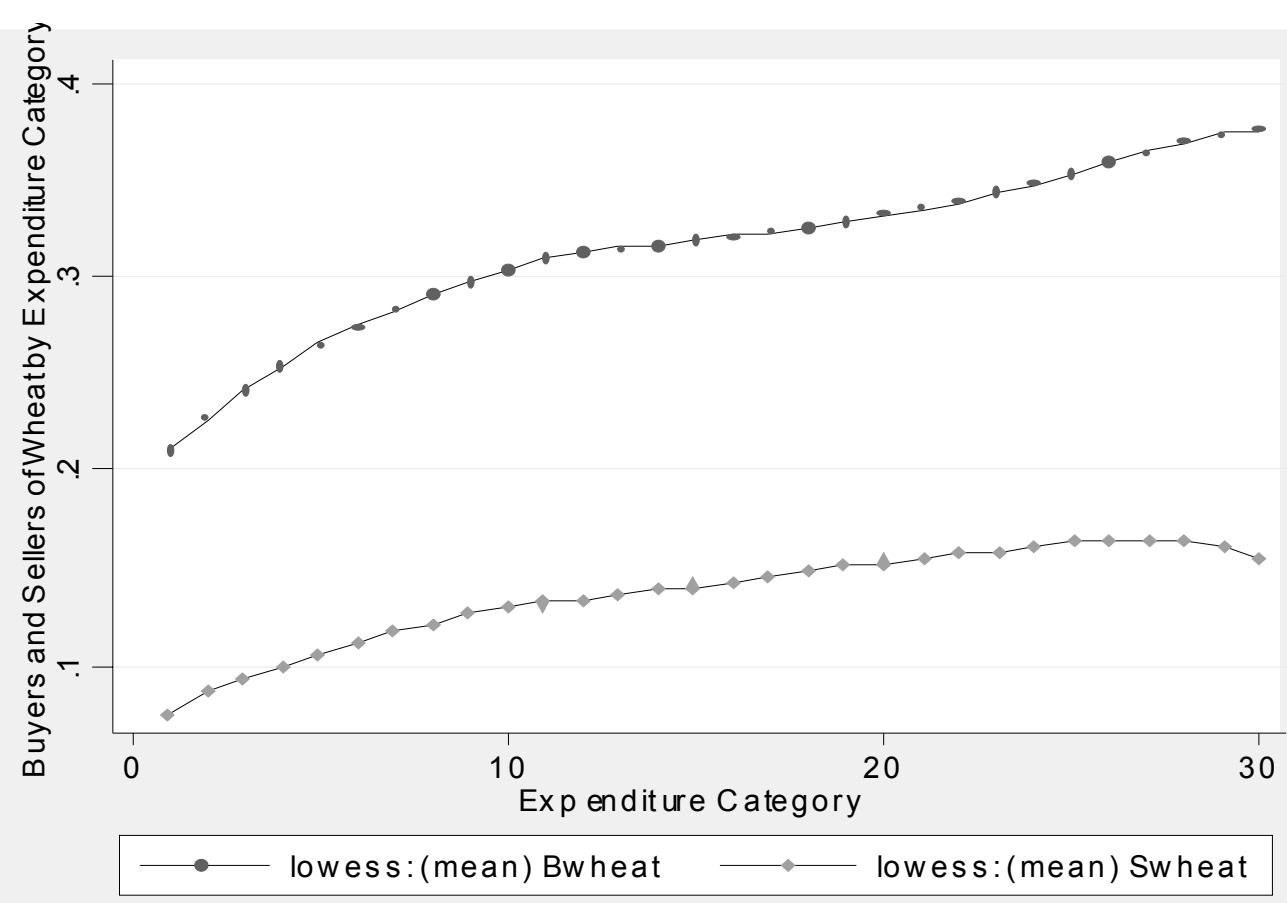


Figure 6: Buyers and Sellers of Wheat by Expenditure Category - Urban Population

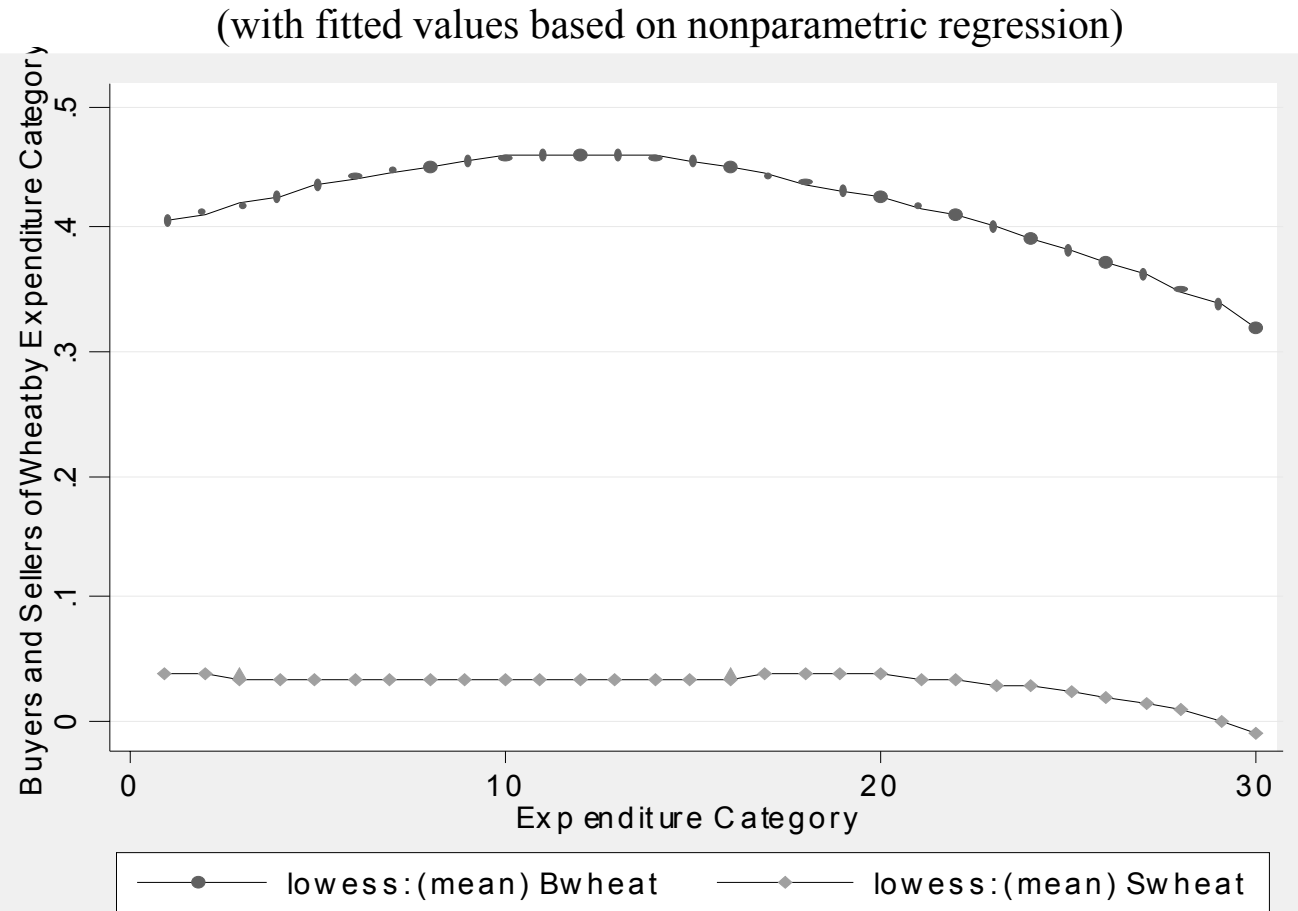


Figure 7: Buyers and Sellers of Wheat by Expenditure Category - Tigray

(with fitted values based on nonparametric regression)

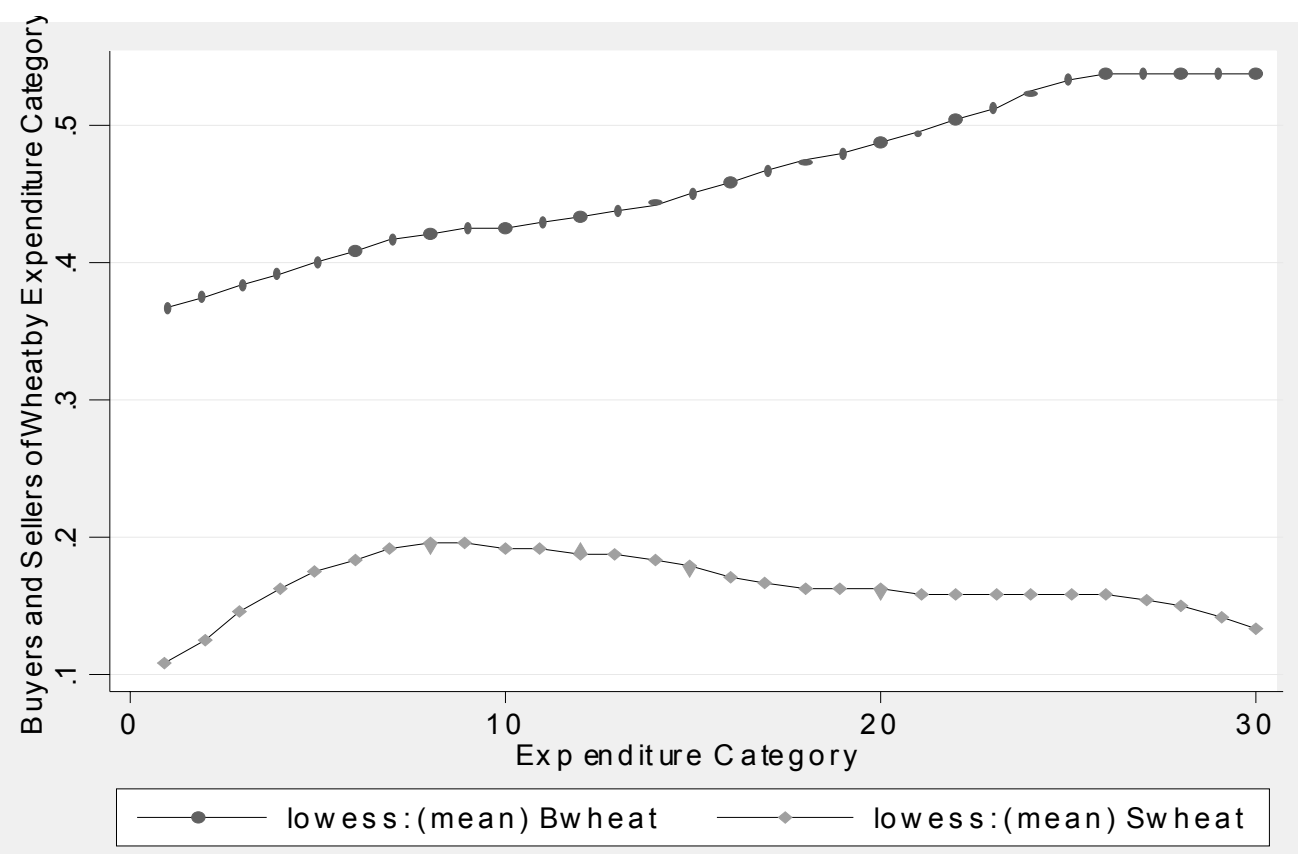


Figure 8: Buyers and Sellers of Wheat by Expenditure Category - Amhara

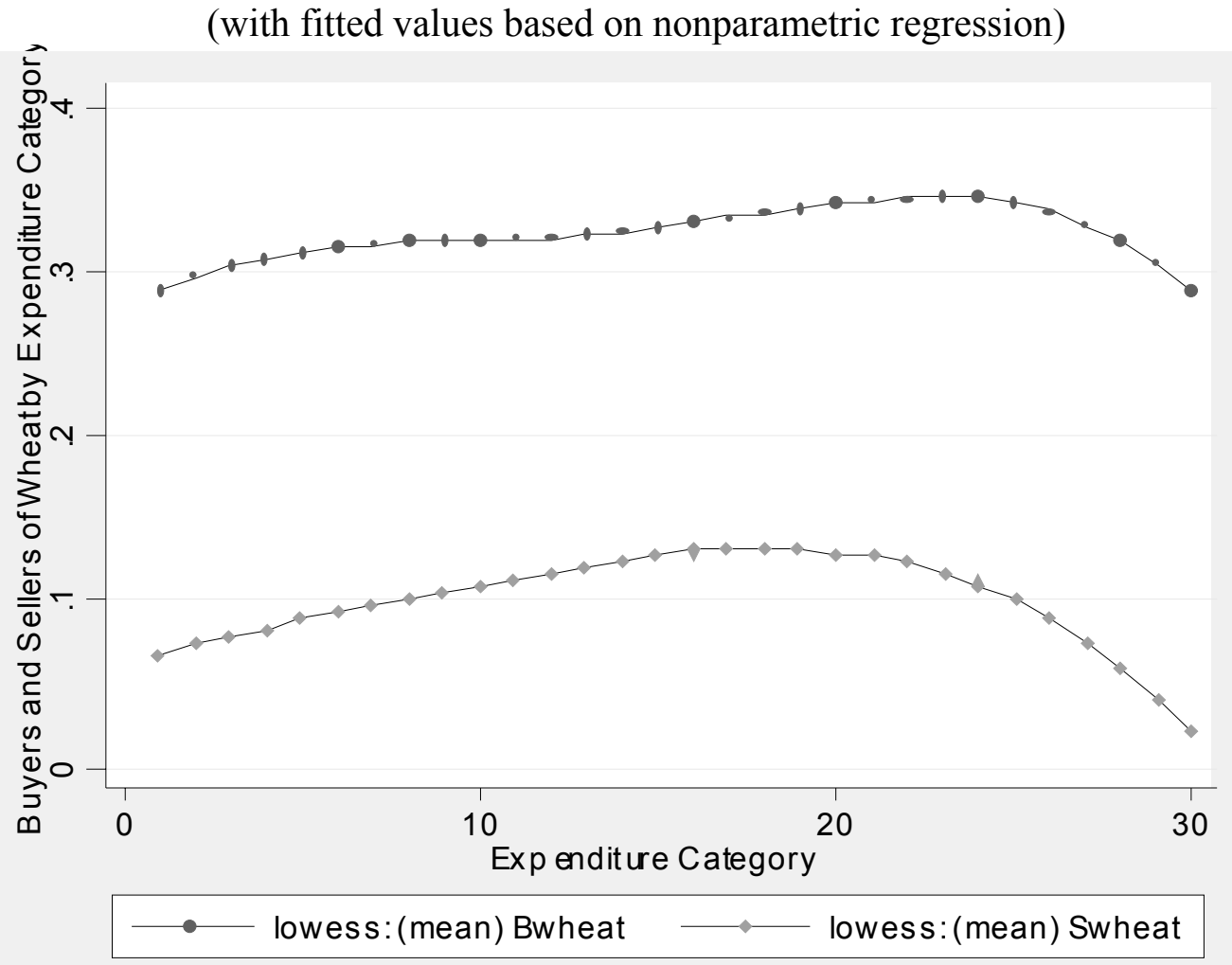


Figure 9: Buyers and Sellers of Wheat by Expenditure Category - Entire Oromiya (with fitted values based on nonparametric regression)

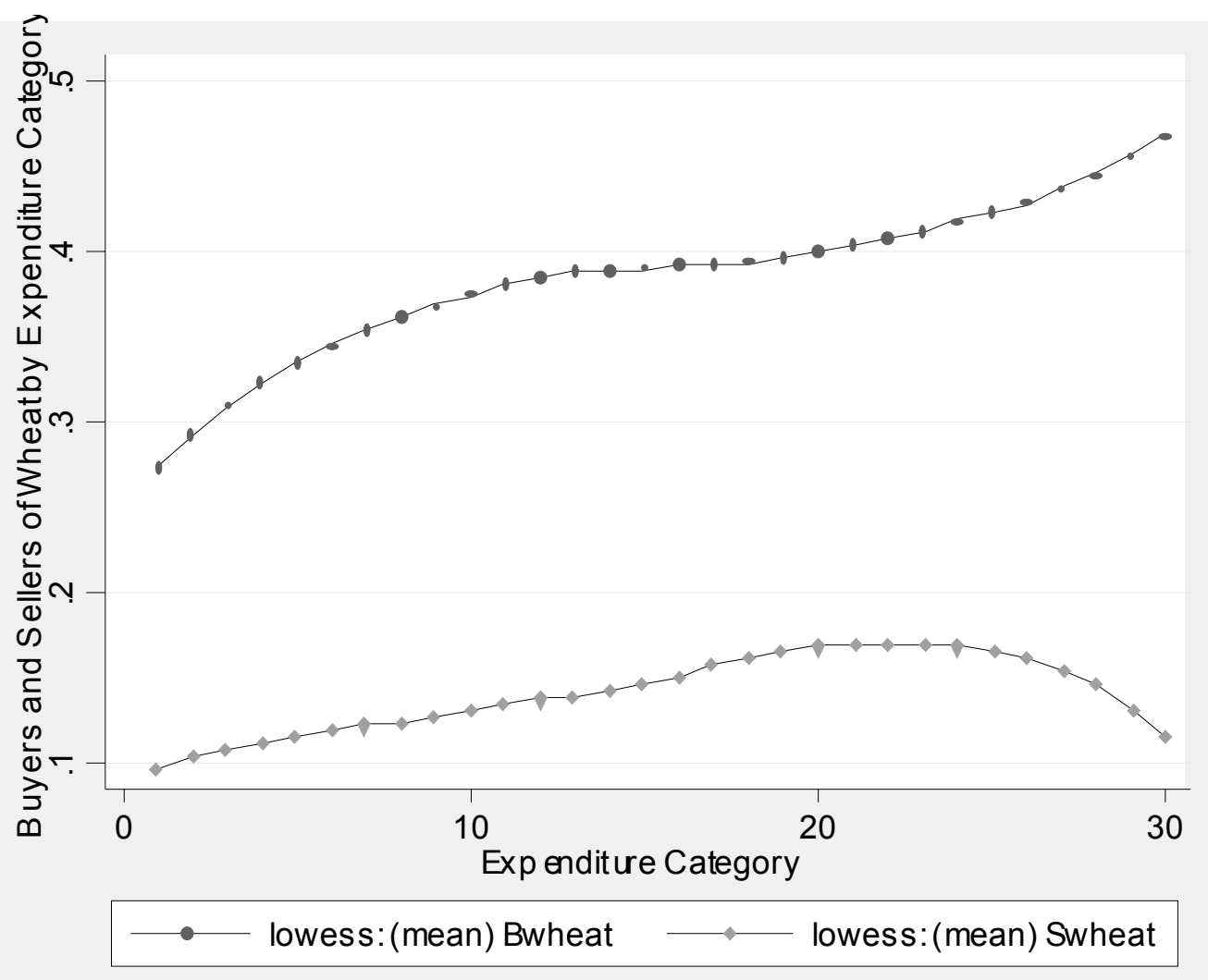


Figure 10: Buyers and Sellers of Wheat by Expenditure Category - SNNPR (with fitted values based on nonparametric regression)

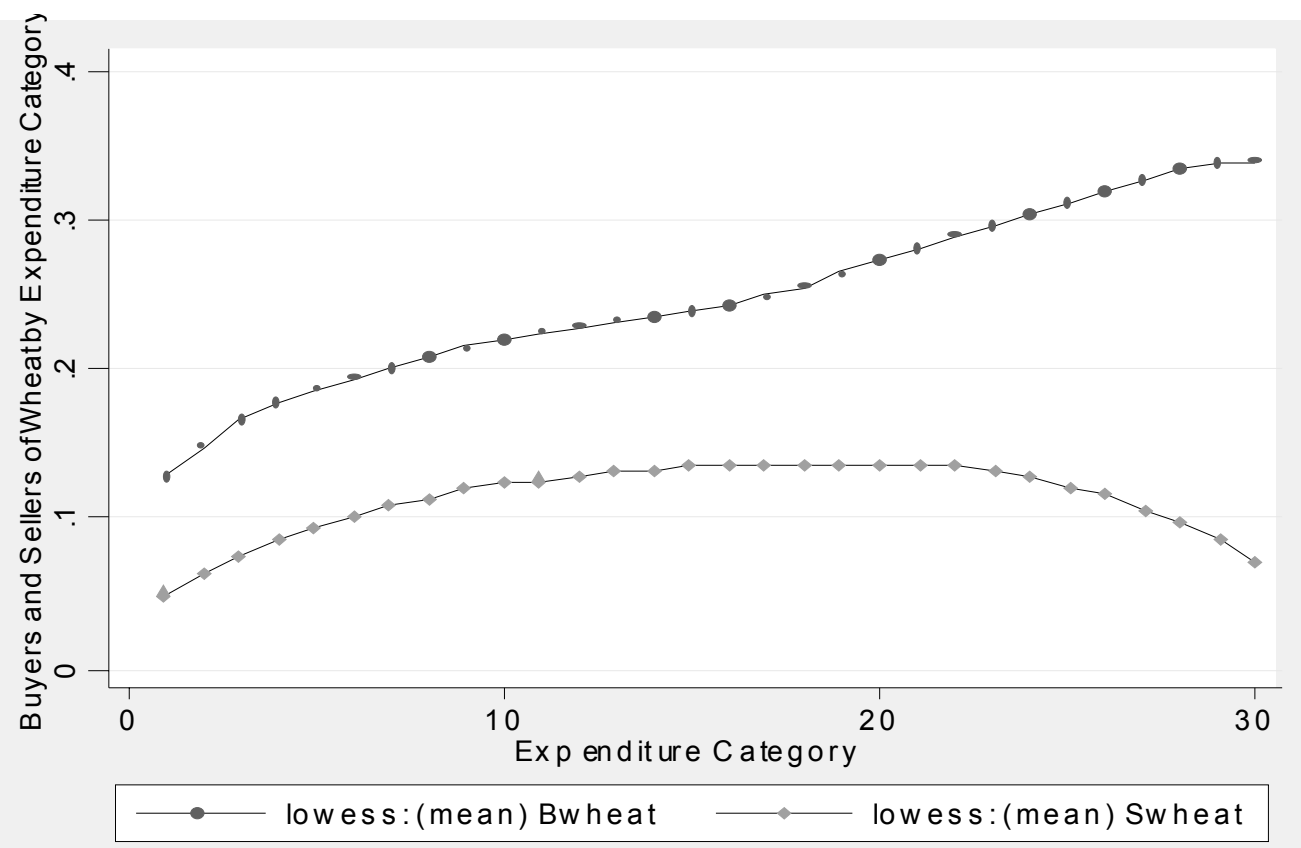


Figure 11: Buyers and Sellers of Wheat by Expenditure Category - Addis Ababa (with fitted values based on nonparametric regression)

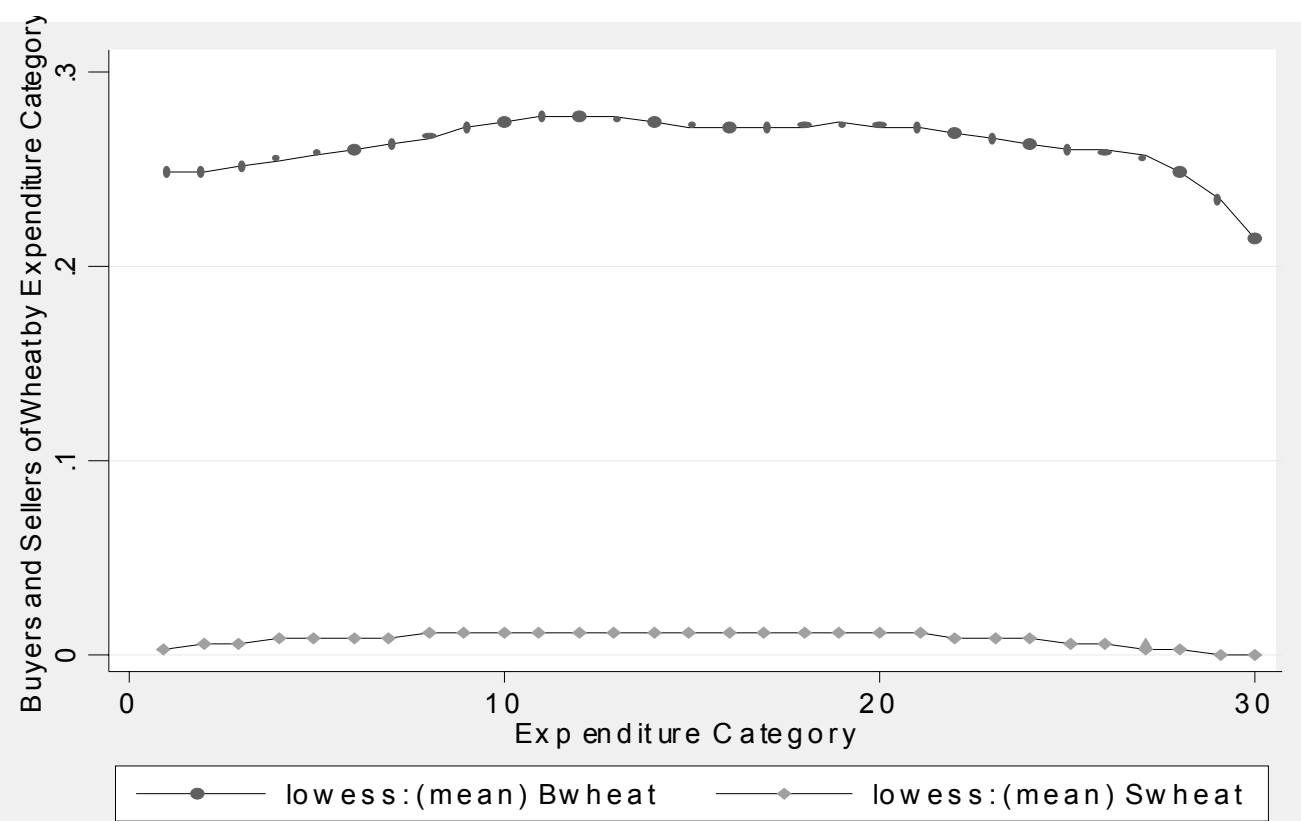


Figure 12: Net Sellers of Wheat by Expenditure Category - Entire Country

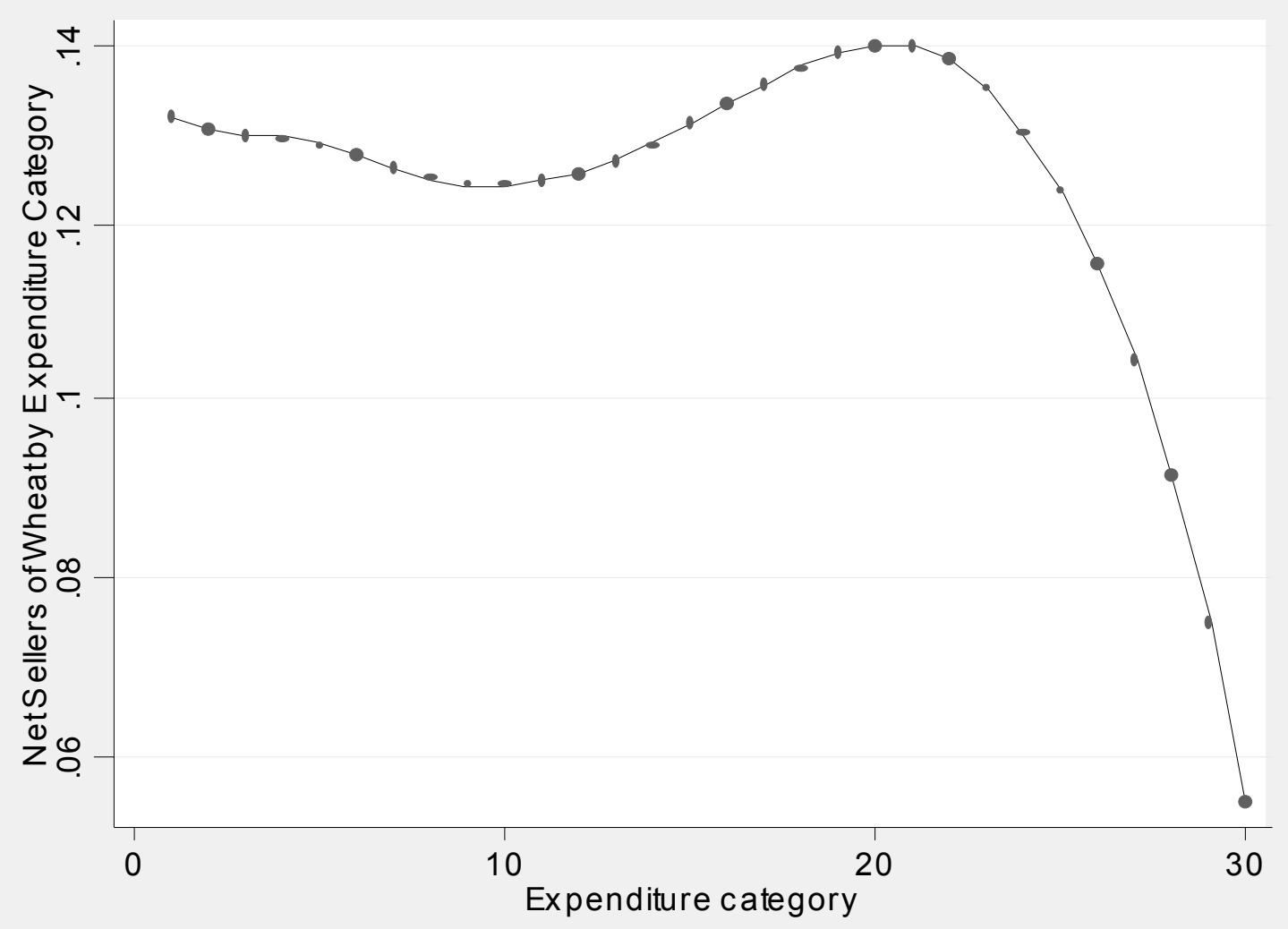


Figure 13: Net Sellers of Wheat by Expenditure Category - Rural Population

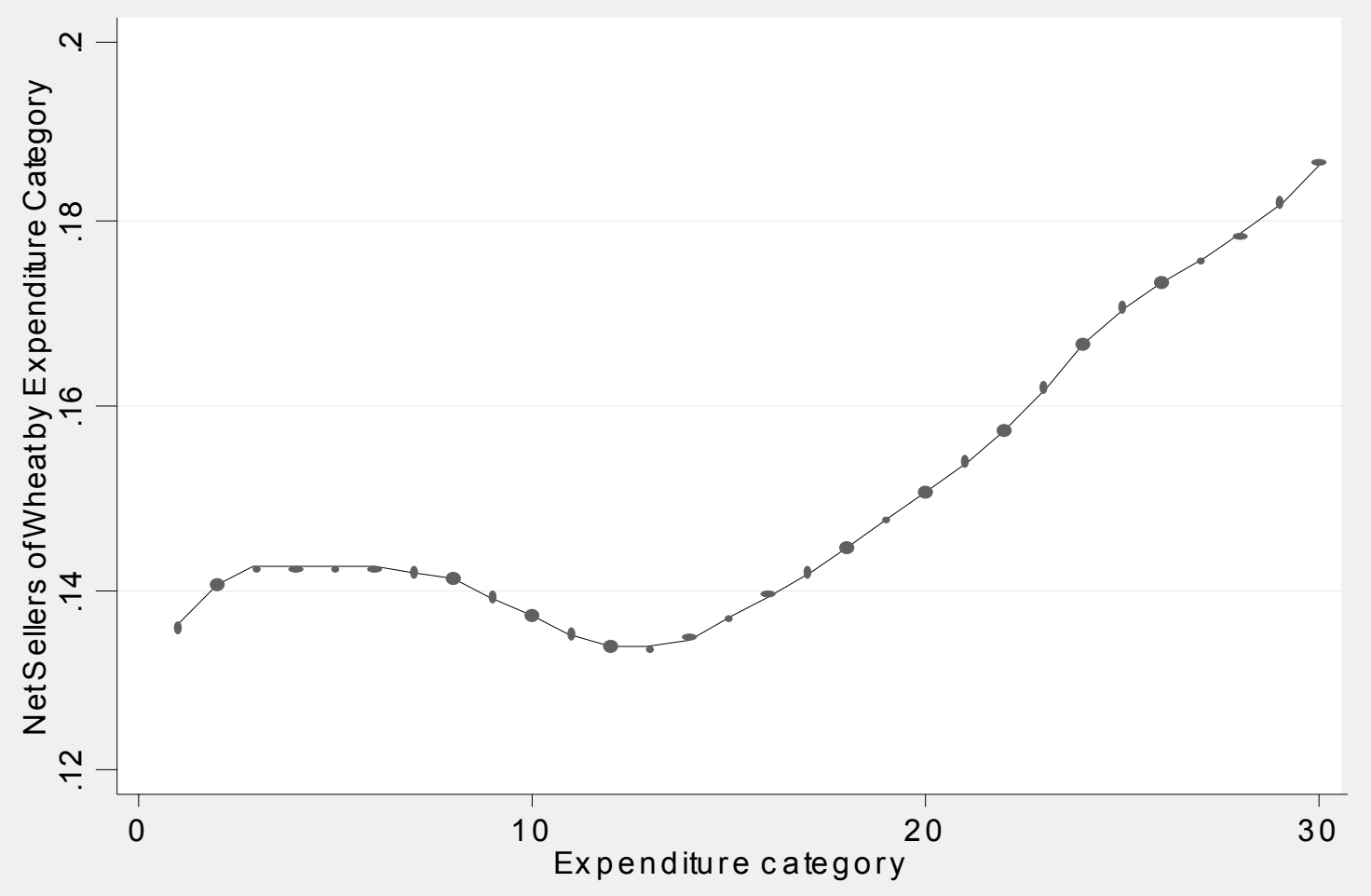


Figure 14: Net Sellers of Wheat by Expenditure Category - Urban Population

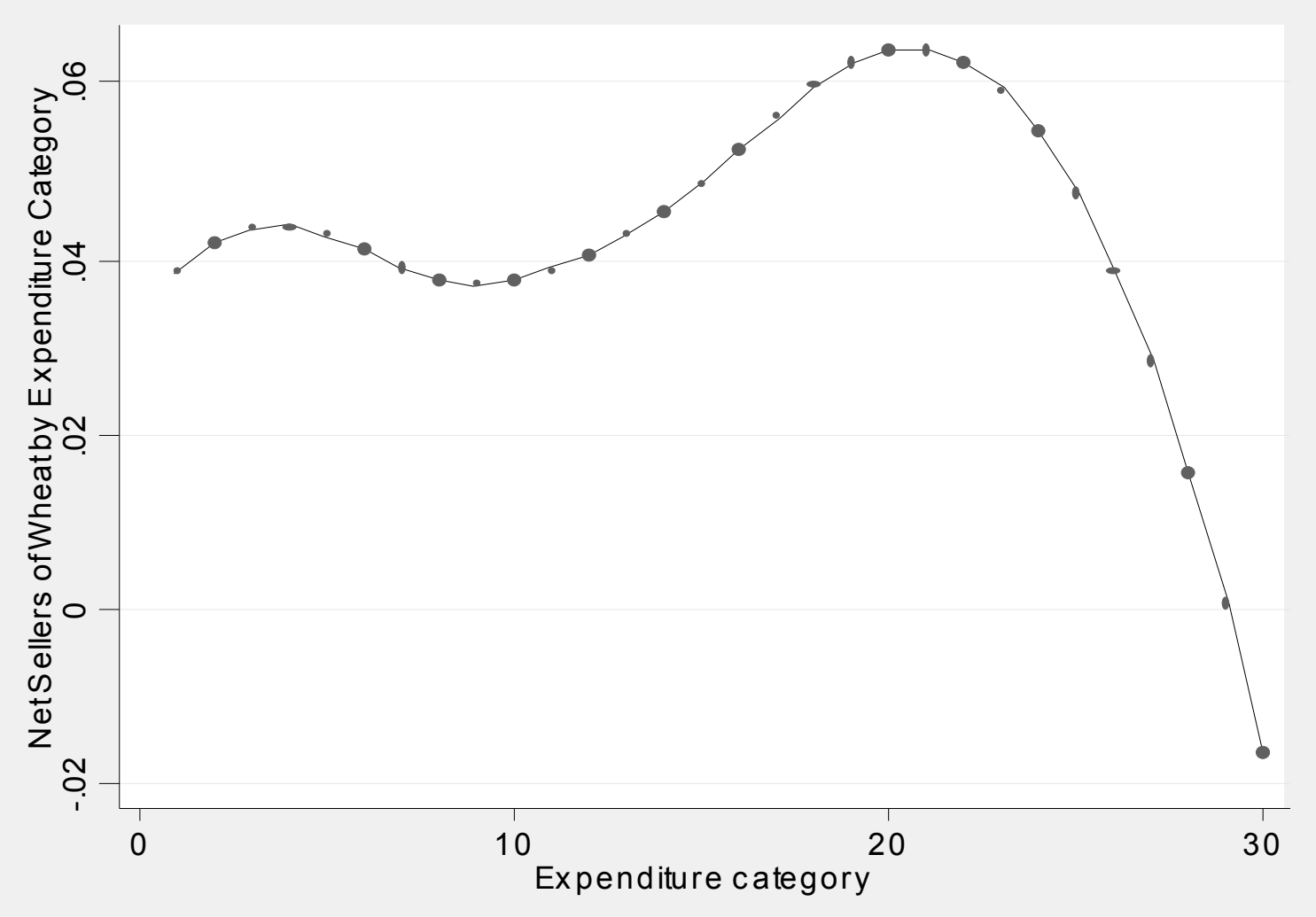


Figure 15: Net Benefit Ratio by Expenditure Category - Entire Country

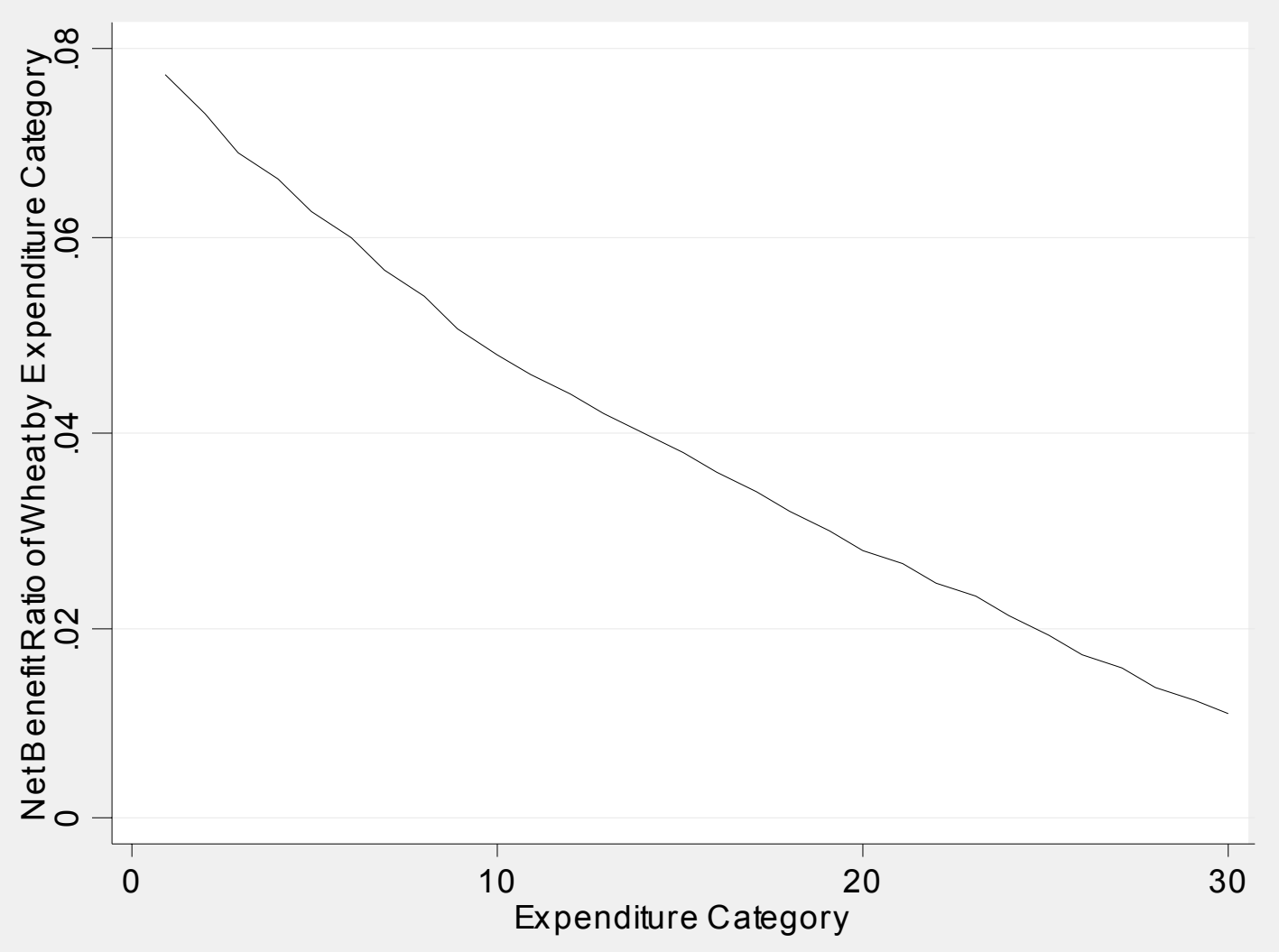


Figure 16: Net Benefit Ratio by Expenditure Category - Rural Population

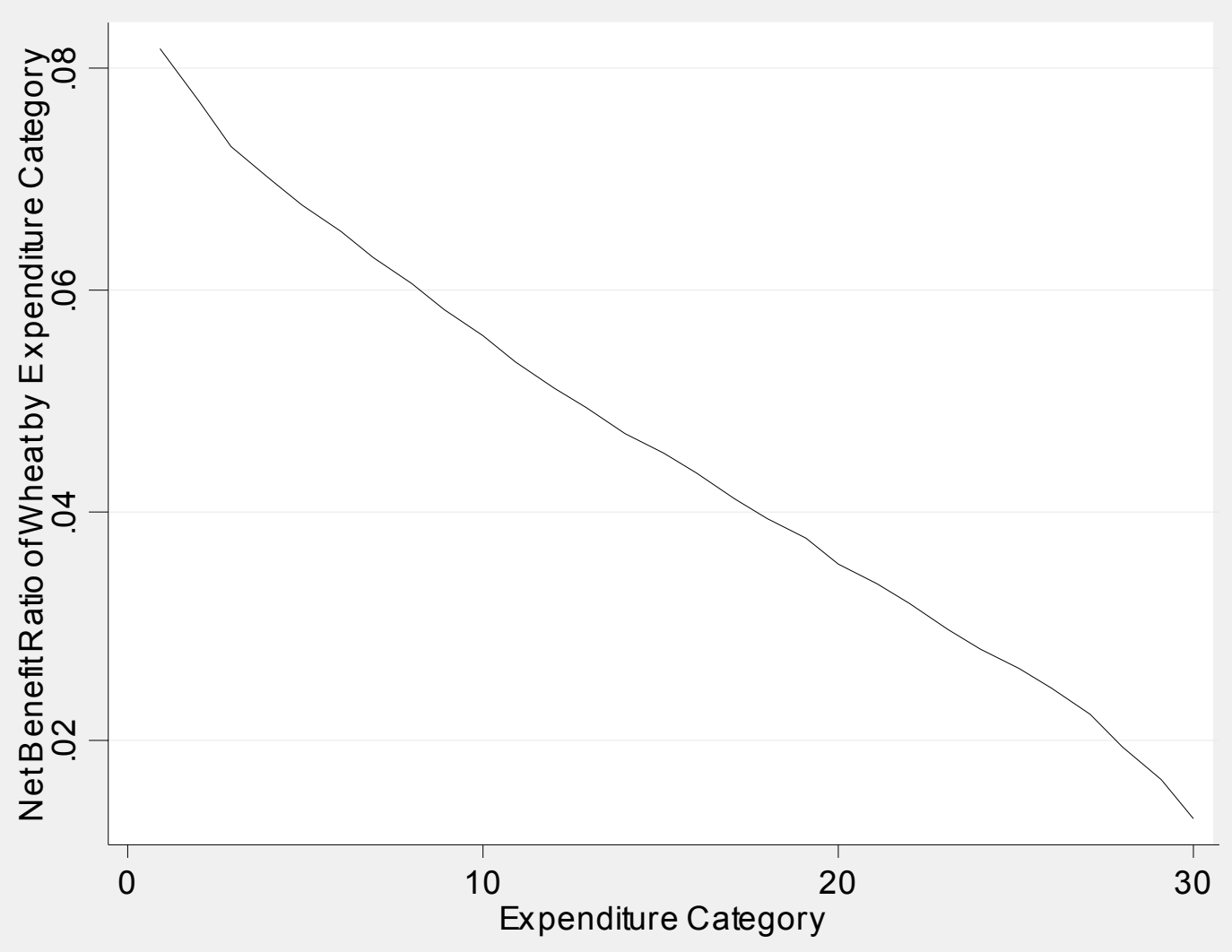


Figure 17: Net Benefit Ratio by Expenditure Category - Urban Population

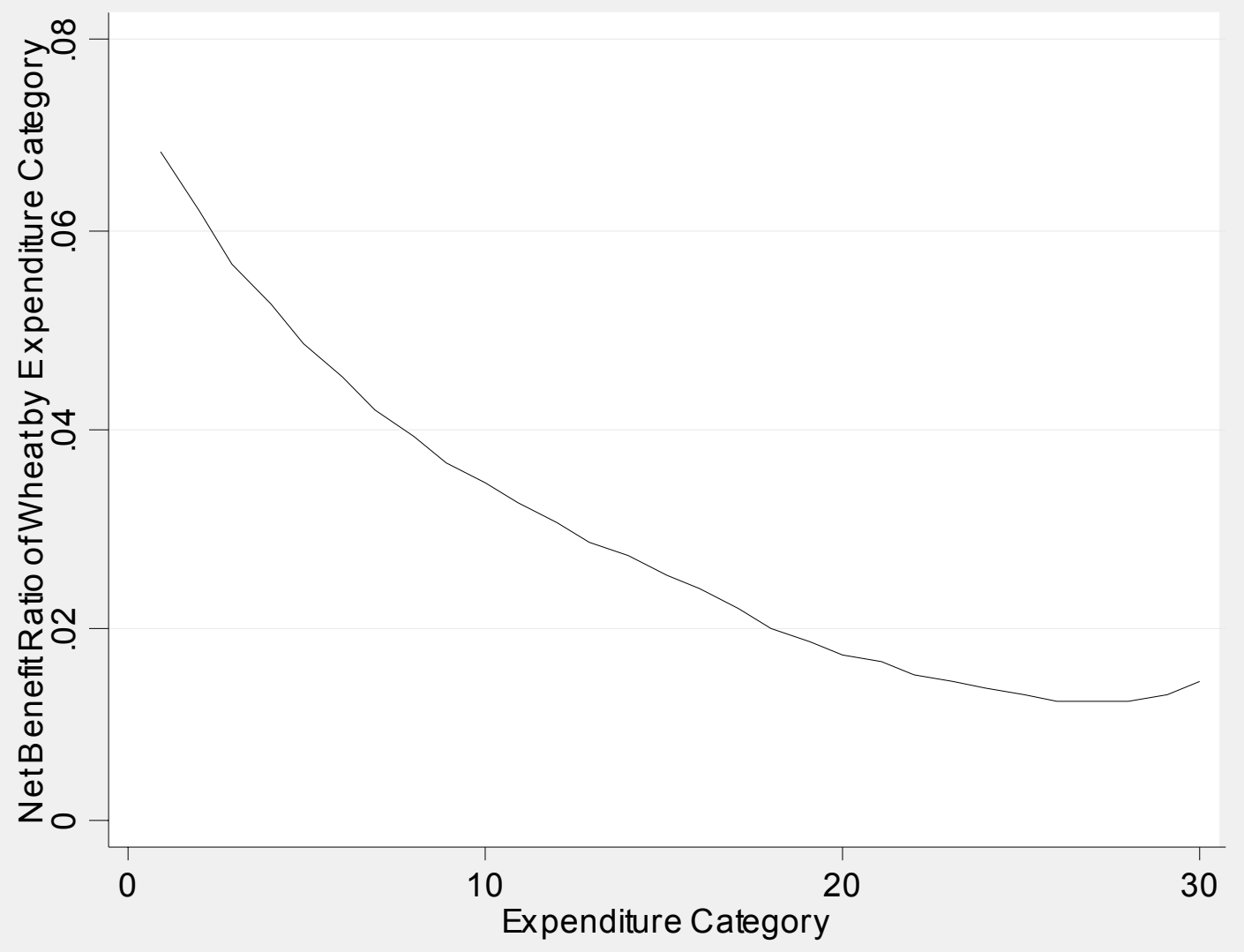


Figure 18

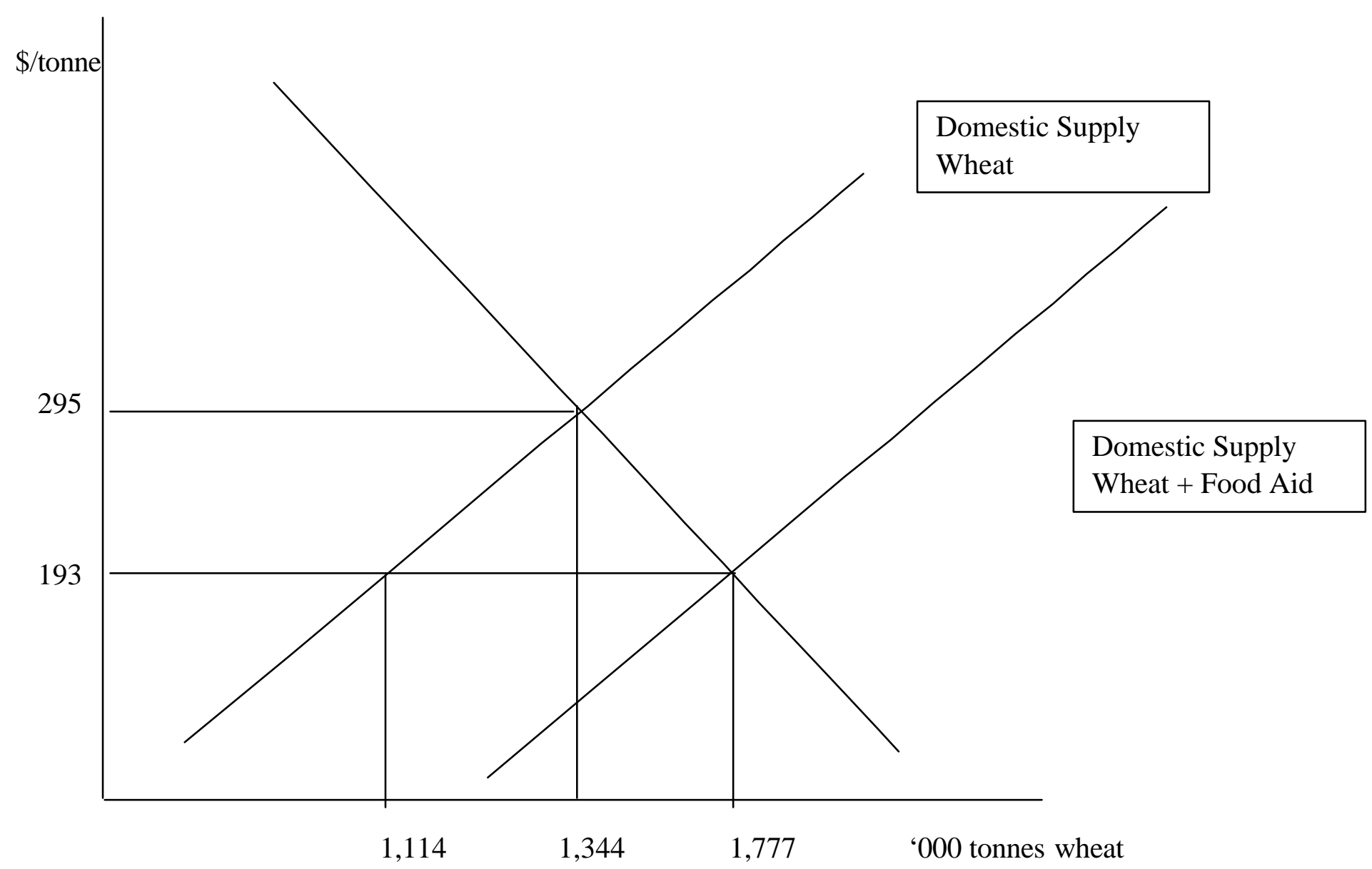

Notes: $\$ 193$ is the production weighted (by region) average of producer prices for wheat received in Ethiopia in 1999 converted at the average nominal exchange rate of 8.23 Birr/US dollar. 1,114 is total thousands of tonnes of wheat produced in Ethiopia in 1999. 1,777 is total thousands of tonnes of wheat consumed in Ethiopia in 1999 or 1,114 plus food aid equal to 663 thousand tonnes of wheat. $\$ 295$ is the price that would prevail in the market if food aid wheat were not imported. It is obtained assuming constant elasiticity of supply and demand functions, an elasticity of supply of wheat equal to .45 and an elasticity of demand for wheat equal to -.6. 
Appendix Figure 1: Living Standards of Entire Population by Urban/Rural

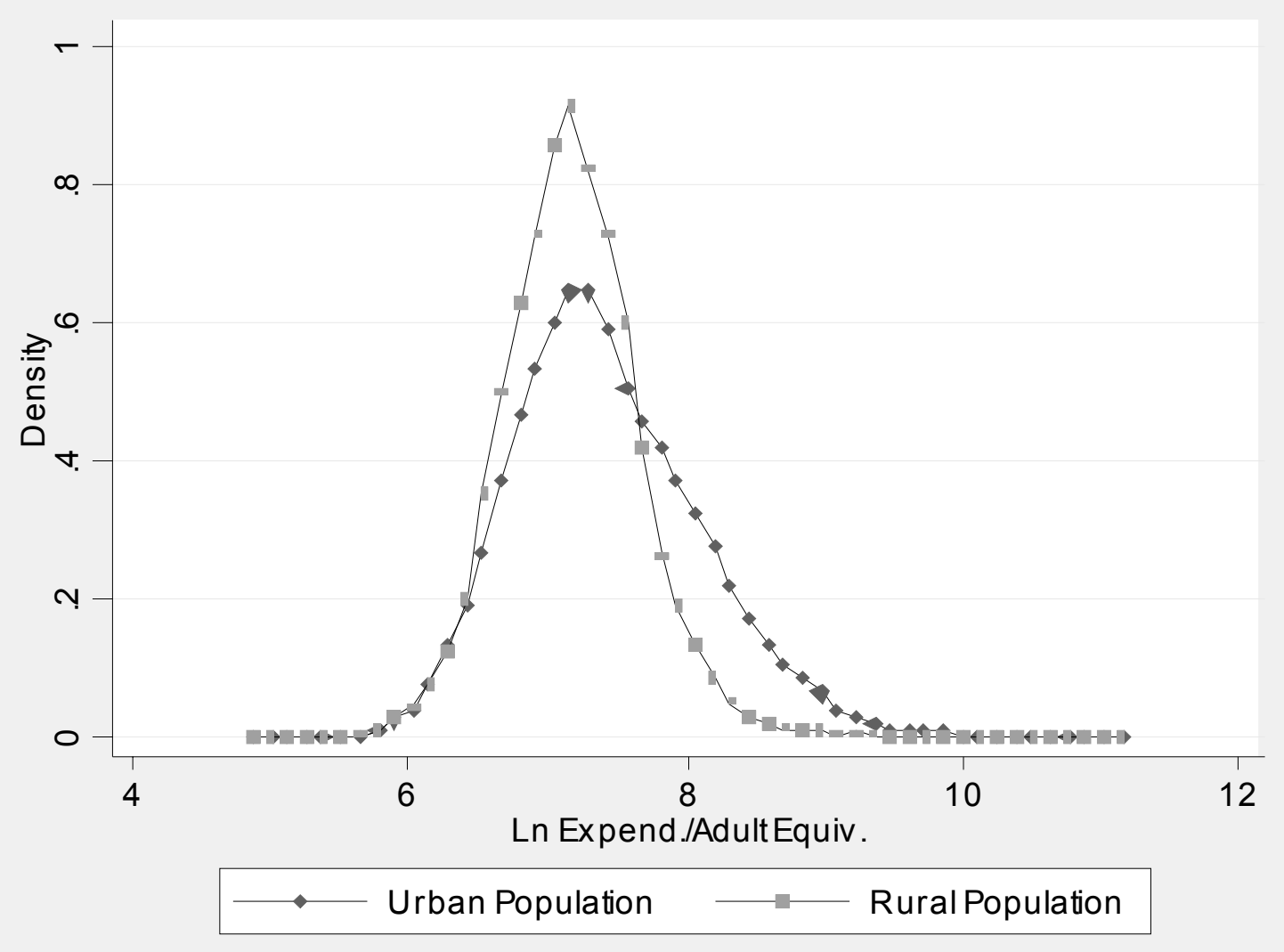




\section{References}

Abbott, P.C. and L.M. Young. 2003. "Export Competition Issues in the Doha Round." Paper for the conference Agricultural Policy Reform and the WTO: Where Are We Heading? Capri, Italy, June 23-26.

Barrett, C. B., "Food Aid: Is it Development Assistance, Trade Promotion, Both or Neither?"American Journal of Agricultural Economics 80 (1998):566-71.

Barrett, C. B. and Dorosh, P. A., 'Nonparametric Evidence from Rice in Madagascar,' American Journal of Agricultural Economics, 78: 656-669, August 1996.

Bezuneh, Mesfin, Deaton, Brady and Zuhair, Segu, "Food Aid Disincentives: The Tunisian Experience," Review of Development Economics, vol. 7, no. 4, November 2003, pp. 609-21

Central Statistical Authority (CSA), Federal Democratic Republic of Ethiopia, 2001a. Report on the 1999/2000 Household Income, Consumption, and Expenditure. Addis Ababa, March, 2002.

Central Statistical Authority (CSA), Federal Democratic Republic of Ethiopia, 2001b. Report on the 1999/2000 Welfare Monitoring Survey. Vol I and Vol II. Addis Ababa, 2002.

Deaton, Angus, "Rice Prices and Income Distribution in Thailand: A Non-Parametric Analysis," The Economic Journal, Volume 99, Issue 395, Supplement:Conference Papers (1989), pp. 1-37

Deaton, Angus, The Analysis of Household Surveys: A Microeconometric Approach to Development Policy, Johns Hopkins University Press, Baltimore, Maryland, 1997

Degefe, Befekadu, Berhanu Nega, and Getahun Tafesse, eds. 2000. First Annual Report on the Ethiopian Economy. V.II, 2000/2001. Ethiopian Economic Association, Addis Ababa.

Degefe, Befekadu, Berhanu Nega, and Getahun Tafesse, eds. 2001. Second Annual Report on the Ethiopian Economy. V.II, 2000/2001. Ethiopian Economic Association, Addis Ababa.

Dercon, Stefan and Pramila Krishnan "Food Aid and Informal Insurance," CSAE Working Paper WPS/2003-01, January 28, 2003

GebreMichael, Amdetsion, " The Impact of Gloabalization - its promises and perils to the Ethiopian Economy," Presented at the Second International Conference on the Ethiopian Economy organized by the Ethiopian Economics Association, June 2004

Gabre-Madhin, Eleni, Email communication December 7, 2004. 
Harrison, Paul, "Ethiopia: Grain Marketing - Review of Recent Trends," Unpublished report for the World Bank, August 2002.

Hamory, Joan and Margaret McMillan, "What Will it Take to Raise Rural Incomes in Ethiopia?" Tufts University, February, 2003.

Jayne, Thomas S., John Strauss, Takashi Yamano and Daniel Molla, "Targeting of Food Aid in Rural Ethiopia: Chronic Need or Inertia?"Journal of Development Economics, vol. 68, no. 2, August 2002, pp. 247-88

Maxwell, S. J. and H. W. Singer, "Food Aid to Developing Countries: a Survey,"World Development, 7 (1970):225-47.

McCalla, Alex F. and Valdes, Alberto, "Diversification and International Trade," in Food security, diversification and resource management: Refocusing the role of agriculture? Proceedings of the Twenty-third International Conference of Agricultural Economists held at Sacramento, California, 10-16 August 1997. 1999, pp. 113-25

Panagariya, Arvind. 2002."Trade and Food Security: Conceptualizing the Linkages.” Paper prepared for presentation at the Conference on Trade, Agricultural Development, and Food Security: The Impact of Recent Economic and Trade Policy Reform, Food and Agricultural Organization, Rome, July 11-12.

Peacemaker-Arrand, Bethany, "The Impact of a New WTO Agricultural Agreement on Cereals Markets in Sub-Saharan Africa," Tufts University, May 2004

Regmi, Anita, M.S. Deepak, James L. Seale, Jr, and Jason Bernstein. 2001. "Cross Country Analysis of Food Consumption Patterns." The Changing Structure of Global Food Consumption and Trade, WRS-01-1, Economic Research Service, USDA.

Schultz, T. W., "Value of US Farm Surpluses to Underdeveloped Countries,"Journal of Farm Economics 42 (1960):1019-30.

Soledad Bos, Maria. 2003. The Impact of Maize Subsidies on Sub-Saharan Africa. M.P.P. Thesis, University of California-Berkeley.

World Food Programme, Shipping Bulletins, WFP, Addis Ababa, 1995 - 2001. 